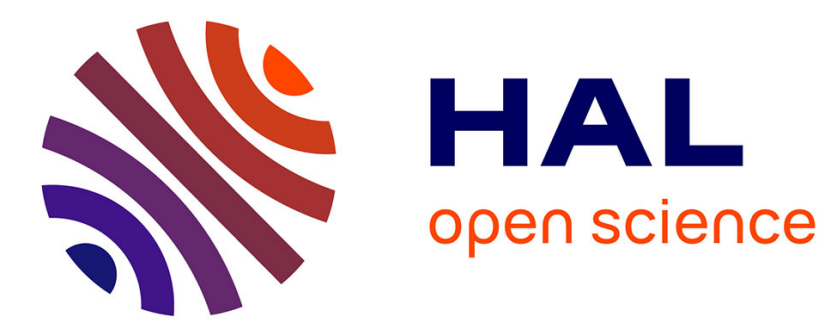

\title{
Impact of gradients at the martian terminator on the retrieval of ozone from SPICAM/MEx
}

Arianna Piccialli, Ann Carine Vandaele, Loic Trompet, Lori Neary, Sebastien

Viscardy, Justin-Tyler Erwin, Anni Määttänen, Frank Daerden, Yannick

Willame, Severine Robert, et al.

\section{To cite this version:}

Arianna Piccialli, Ann Carine Vandaele, Loic Trompet, Lori Neary, Sebastien Viscardy, et al.. Impact of gradients at the martian terminator on the retrieval of ozone from SPICAM/MEx. Icarus, 2021, 353 (January), pp.art. 113598. 10.1016/j.icarus.2019.113598 . insu-02422316

\section{HAL Id: insu-02422316 \\ https://hal-insu.archives-ouvertes.fr/insu-02422316}

Submitted on 18 Nov 2020

HAL is a multi-disciplinary open access archive for the deposit and dissemination of scientific research documents, whether they are published or not. The documents may come from teaching and research institutions in France or abroad, or from public or private research centers.
L'archive ouverte pluridisciplinaire HAL, est destinée au dépôt et à la diffusion de documents scientifiques de niveau recherche, publiés ou non, émanant des établissements d'enseignement et de recherche français ou étrangers, des laboratoires publics ou privés. 


\section{Journal Pre-proof}

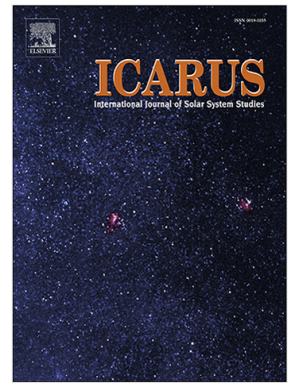

Impact of gradients at the Martian terminator on the retrieval of ozone from SPICAM/MEx

A. Piccialli, A.C. Vandaele, L. Trompet, L. Neary, S. Viscardy, J.T. Erwin, A. Määttänen, F. Daerden, Y. Willame, S. Robert, S. Aoki, V. Wilquet, F. Lefèvre, F. Montmessin

PII: $\quad$ S0019-1035(19)30292-1

DOI: $\quad$ https://doi.org/10.1016/j.icarus.2019.113598

Reference: $\quad$ YICAR 113598

To appear in: $\quad$ Icarus

Received date: 22 April 2019

Revised date: 22 October 2019

Accepted date : 6 December 2019

Please cite this article as: A. Piccialli, A.C. Vandaele, L. Trompet et al., Impact of gradients at the Martian terminator on the retrieval of ozone from SPICAM/MEx. Icarus (2019), doi:

https://doi.org/10.1016/j.icarus.2019.113598.

This is a PDF file of an article that has undergone enhancements after acceptance, such as the addition of a cover page and metadata, and formatting for readability, but it is not yet the definitive version of record. This version will undergo additional copyediting, typesetting and review before it is published in its final form, but we are providing this version to give early visibility of the article. Please note that, during the production process, errors may be discovered which could affect the content, and all legal disclaimers that apply to the journal pertain.

(C) 2019 Published by Elsevier Inc. 


\title{
Impact of gradients at the Martian terminator on the retrieval of ozone from SPICAM/MEx
}

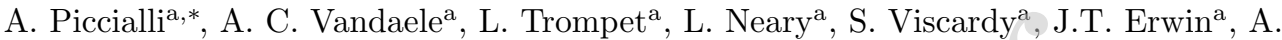 \\ Määttänen ${ }^{\mathrm{b}}$, F. Daerden ${ }^{\mathrm{a}}$, Y. Willame ${ }^{\mathrm{a}}$, S. Robert ${ }^{\mathrm{a}}$, S. Aoki ${ }^{\mathrm{a}}$, V. Wilquet ${ }^{\mathrm{a}}$, F. Lefèvre $^{\mathrm{b}}$, F. \\ Montmessin ${ }^{\mathrm{C}}$ \\ ${ }^{a}$ Planetary Aeronomy, Royal Belgian Institute for Space Aeronomy, 3 av. Circulaire, B-1180 Brussels, Belgium \\ ${ }^{b}$ LATMOS/IPSL, Sorbonne Université, UVSQ, CNRS, Paris, France \\ ${ }^{c}$ LATMOS/IPSL, UVSQ Université Paris-Saclay, Sorbonne université, CNRS, Guyancourt, France
}

\begin{abstract}
Rapid variations of pressure, temperature and illumination at the day-night terminator have the potential to cause asymmetries in the abundance distribution of the atmosphere constituents along the line of sight (LOS) of a solar occultation experiment. Ozone, in particular, displays steep density gradients across the terminator of Mars due to photolysis. Nowadays, most of the retrieval algorithms for solar and stellar occultations rely on the assumption of a spherically symmetrical atmosphere. However, photochemically induced variations near sunrise/sunset conditions need to be taken into account in the retrieval technique in order to prevent inaccuracies.

We investigated the impact of gradients along the LOS of the solar occultation experiment SPICAM/Mars Express for the retrieval of ozone under sunrise/sunset conditions. In order to test the impact of different gradients, we selected four occultations at sunrise and at sunset each. Sunset occultations are located near the equator, while sunrise observations are situated at high latitudes in the South, because of the geometry of the orbit.
\end{abstract}

We used the diurnal variations in the ozone concentration obtained from a three-dimensional General Circulation Model (GEM-Mars) together with an adapted radiative transfer code (ASIMUT). The General Circulation Model (GCM) suggests that ozone variations strongly depend on latitude,

\footnotetext{
* Corresponding author

Email addresses: arianna.piccialli@aeronomie.be (A. Piccialli), A-C.Vandaele@aeronomie.be (A. C. Vandaele), Loic.Trompet@aeronomie.be (L. Trompet), Lori.Neary@aeronomie.be (L. Neary), Sebastien.Viscardy@aeronomie.be (S. Viscardy), justin-tyler.erwin@aeronomie.be (J.T. Erwin), anni.maattanen@latmos.ipsl.fr (A. Määttänen), Frank.Daerden@aeronomie.be (F. Daerden), yannick.willame@aeronomie.be (Y. Willame), Severine.Robert@aeronomie.be (S. Robert), Shohei.Aoki@aeronomie.be (S. Aoki), Valerie.Wilquet@aeronomie.be (V. Wilquet), franck.lefevre@latmos.ipsl.fr (F. Lefèvre), franck.montmessin@latmos.ipsl.fr (F. Montmessin) 
altitude, and season. As shown by the model, near the equator and below $25 \mathrm{~km}$, ozone changes only slightly with local time. Around $45 \mathrm{~km}$, the density changes by several orders of magnitude across the terminator. At high latitudes in the South, during northern winter time, ozone variations at the terminator are negligible.

The impact of gradients on ozone retrievals is strongly related to the local atmospheric structure as predicted by the GCM. Sunset ozone retrievals are smaller than retrievals obtained assuming a spherically symmetrical atmosphere, with a maximum change of about $20 \%$. At sunrise, the impact of gradients on the retrievals is negligible. This behavior can be explained by the specific geometry of sunrise observations, all situated at high latitudes in the South.

Keywords: Mars, atmosphere, Occultations, Ultraviolet observations, Radiative transfer, Photochemistry

\section{Introduction}

Occultation, both solar and stellar, is a powerful technique to measure the vertical distribution of trace gases in planetary atmospheres. The major advantages of this technique are its high vertical resolution and its self-calibration mode. While stellar occultations probe the atmosphere preferably at night time, solar occultation are restricted to the terminator (Bertaux et al., 2006).

The atmosphere of a terrestrial planet at the day-night terminator is a region of great interest characterized by gradients of density and temperature, driven by differences in the solar illumination, and by sharp transitions in the chemical regime. Rapid variations in species concentration at the terminator have the potential to cause asymmetries in the species distributions along the line of sight (LOS) of a solar occultation experiment. Ozone, in particular, displays rapid changes due to photolysis more pronounced on the day side than on the night side (Natarajan et al., 2005; Lefèvre et al., 2004). Nowadays, most of the retrieval algorithms for solar and stellar occultations rely on the assumption of a spherically symmetrical atmosphere (Vandaele et al., 2006; Quémerais et al., 2006). However, photochemically induced variations near sunrise/sunset conditions need to be taken into account in the retrieval process in order to prevent inaccuracies (Boughner et al., 1980; Natarajan et al., 2005). In order to handle concentration gradients along the line of sight it is necessary to improve the retrieval schemes used to analyze occultation observations.

In the present paper, we test an improved retrieval scheme that handles different gradients along the line of sight and we focus in particular on the retrieval of ozone from SPICAM/Mars 
Express solar occultations taking into account variations in the temperature and in the ozone concentration at the day/night terminator. Ozone is a species with a short chemical lifetime and characterized by sharp gradients at the day-night terminator both on Earth and on Mars. On Mars, 3D General Circulation Models (GCMs) predict the existence of two ozone layers (Lefèvre et al., 2004; Daerden et al., 2019), instead of just one layer as on Earth. This was confirmed by SPICAM stellar occultations (Lebonnois et al., 2006), which revealed their existence on the nightside. The first layer is located below $30 \mathrm{~km}$, and the second one - seasonally and spatially variable - is situated at higher altitudes between 30 and $60 \mathrm{~km}$. While the lower layer displays only a weak diurnal cycle, the upper layer is strongly depleted by ultraviolet radiation at sunrise. It reappears as the Sun sets due to the recombination of $\mathrm{O}$ and $\mathrm{O}_{2}$.

Previous observations reported that the largest ozone quantities are observed at high latitudes in the winter hemisphere where water vapour has condensed on the polar cap (Lebonnois et al., 2006; Willame et al., 2017). This was expected since ozone is anti-correlated to water vapour. Lower quantities of ozone are found at low latitudes and in the summer hemisphere (Lefèvre et al., 2004; Daerden et al., 2019).

We briefly describe the SPICAM-UV solar occultation dataset in Section 2. The GCM used as an input for this study is presented in Section 3. We review the retrieval technique in Section 4 and then present the results in Sections 5-7.

\section{SPICAM-UV solar occultation dataset}

SPICAM (SPectroscopie pour l'Investigation des Caractéristiques Atmosphériques de Mars), on board the ESA's mission Mars Express, is a remote sensing spectrometer observing in the ultraviolet $(118-320 \mathrm{~nm})$ and in the near infrared $(1-1.7 \mu \mathrm{m})$. A detailed description of the instrument as well as its scientific objectives can be found in Bertaux et al. (2006). In the solar occultation mode, the UV instrument is used to measure the vertical profiles of $\mathrm{O}_{3}$ and aerosols of the Martian atmosphere (Määttänen et al., 2013). During a solar occultation, the instrument points through the atmosphere toward the Sun as it rises or sets. When the instrument's line of sight to the Sun intersects the atmosphere, the solar light is absorbed by the atmospheric constituents (Quémerais et al., 2006; Montmessin et al., 2006; Forget et al., 2009; Lebonnois et al., 2006). A reference solar spectrum is obtained by recording the solar light above the dense part of the atmosphere (above 
Table 1: Solar occultations analysed in this study. The reference location for each profile is determined at the surface. Ls is the solar longitude.

\begin{tabular}{|c|c|c|c|c|c|}
\hline \hline Occultation & Longitude & Latitude & Ls & Local time & Terminator \\
\hline 00472A02 & 342.76 & -9.23 & 42.37 & 17.82 & Sunset \\
$00584 \mathrm{~A} 02$ & 143.05 & -18.02 & 56.27 & 17.52 & Sunset \\
$00633 \mathrm{~A} 02$ & 10.80 & -21.67 & 62.29 & 17.37 & Sunset \\
$00655 \mathrm{~A} 01$ & 10.25 & -23.46 & 64.99 & 17.30 & Sunset \\
\hline 00584A03 & 47.56 & -68.94 & 56.28 & 11.44 & Sunrise \\
00633A03 & 280.26 & -67.62 & 62.30 & 11.59 & Sunrise \\
00642A02 & 117.83 & -67.42 & 63.40 & 11.65 & Sunrise \\
$00682 \mathrm{~A} 02$ & 157.93 & -66.46 & 68.30 & 12.05 & Sunrise \\
\hline
\end{tabular}

$120 \mathrm{~km}$ ). The ultraviolet sensor of SPICAM has a spectral resolution of $0.51 \mathrm{~nm}$. The vertical sampling resolution obtained in solar occultation is less than $1 \mathrm{~km}$.

Figure 1 displays transmission spectra obtained at different altitudes for the observation 00633A02. The signal below $200 \mathrm{~nm}$ has a poor signal-to-noise ratio (SNR) due to the low emission of the Sun at those wavelengths and is not used in the retrievals. The ozone absorption band (Hartley band) is clearly visible around $250 \mathrm{~nm}$. The aerosols affect the entire spectral range by attenuating the spectrum approximately uniformly (Montmessin et/al., 2006).

The reference location for each occultation is determined at the surface (see Figure 2). However, the relative motion of the source often means that the locus of tangent points is far from vertical, leading to 'slanted' profiles, extending over several hundred kilometers horizontally. A solar occultation profile is then spread over a latitude and longitude interval, usually smaller than $20^{\circ}$. The local time of the tangent point is also changing at each altitude during an occultation. The spread of the occultation profile is larger close to the poles and decreases approaching the equator.

For this study we analyzed data from eight solar occultations acquired by SPICAM-UV between June and August 2004 (MY27) both at sunrise and at sunset (see Table 1). We selected only occultations acquired before June 2005 in order to avoid the oscillations caused by the MARSIS/MEx antenna (Määttänen et al., 2013). Due to such a constraint, there is a clear bias in the geolocalization of sunrise and sunset occultations: all sunset occultations are located near the equator while sunrise occultations are situated at high latitudes. 


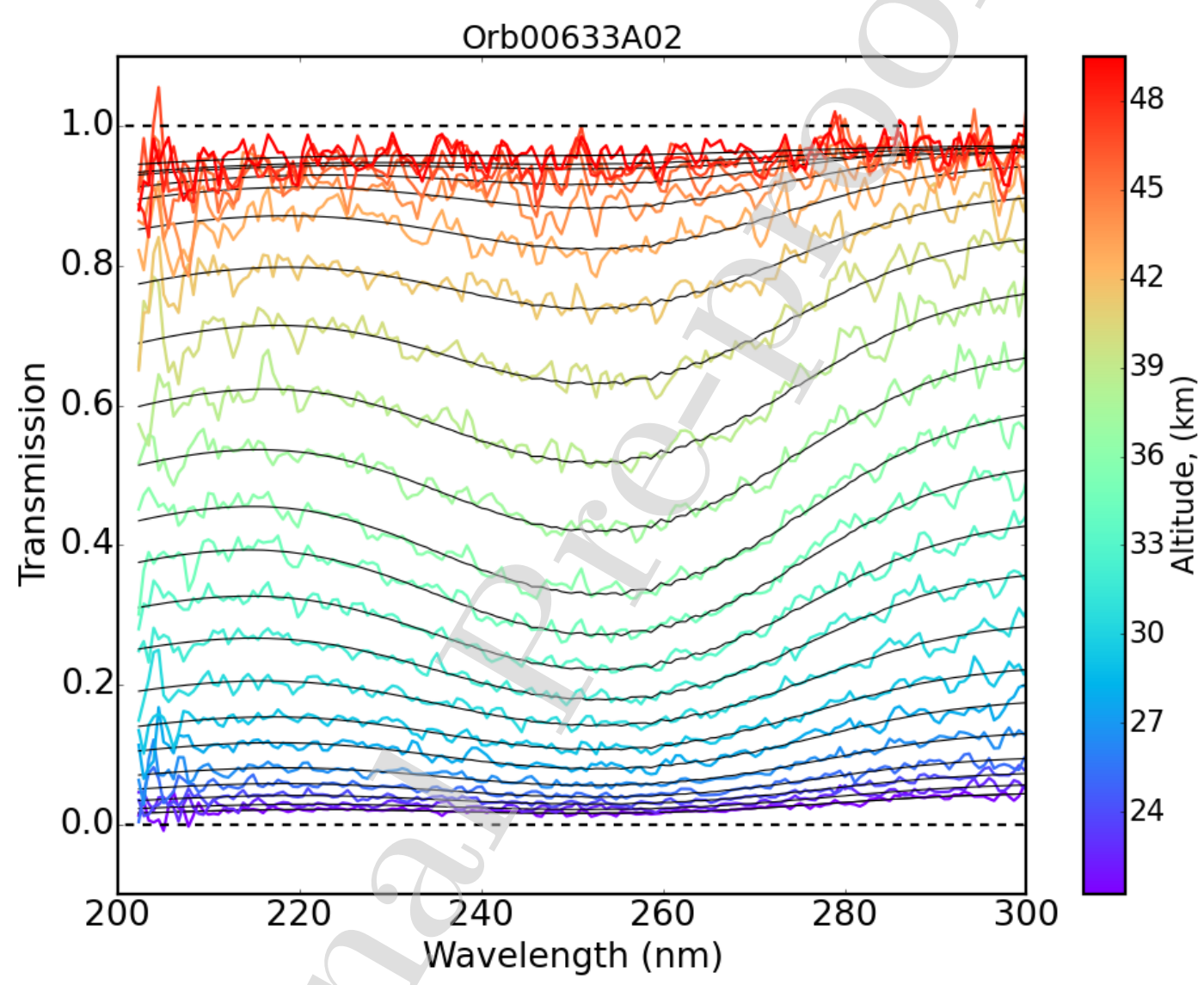

Figure 1: Example of SPICAM transmission spectra at different altitudes: (blue) low altitudes; (red) high altitudes. Black lines are fitted spectra calculated using the radiative transfer code ASIMUT. 


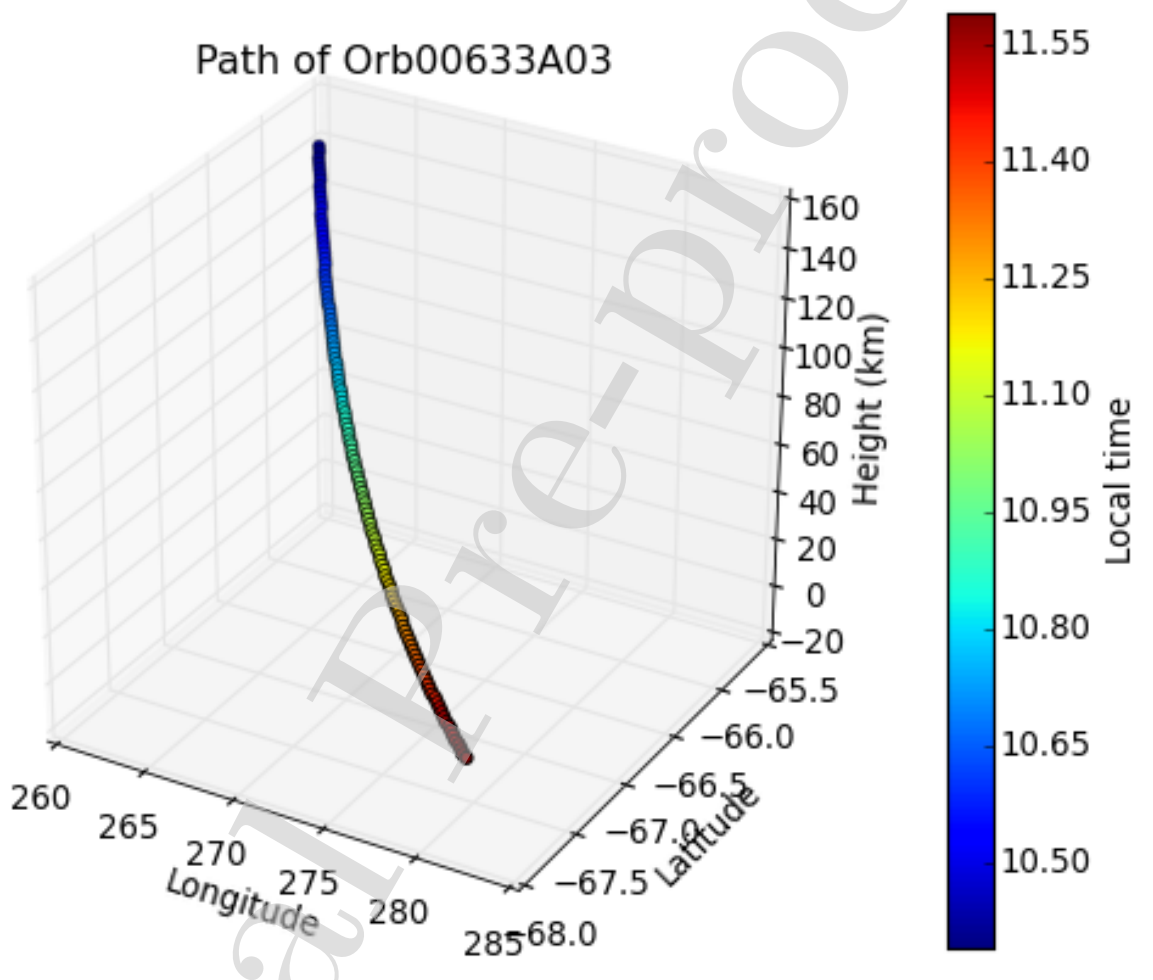

Figure 2: Example of path described by the tangent point during an occultation (\#00633A03). The colorbar shows the local time (hr) variation along the path. 


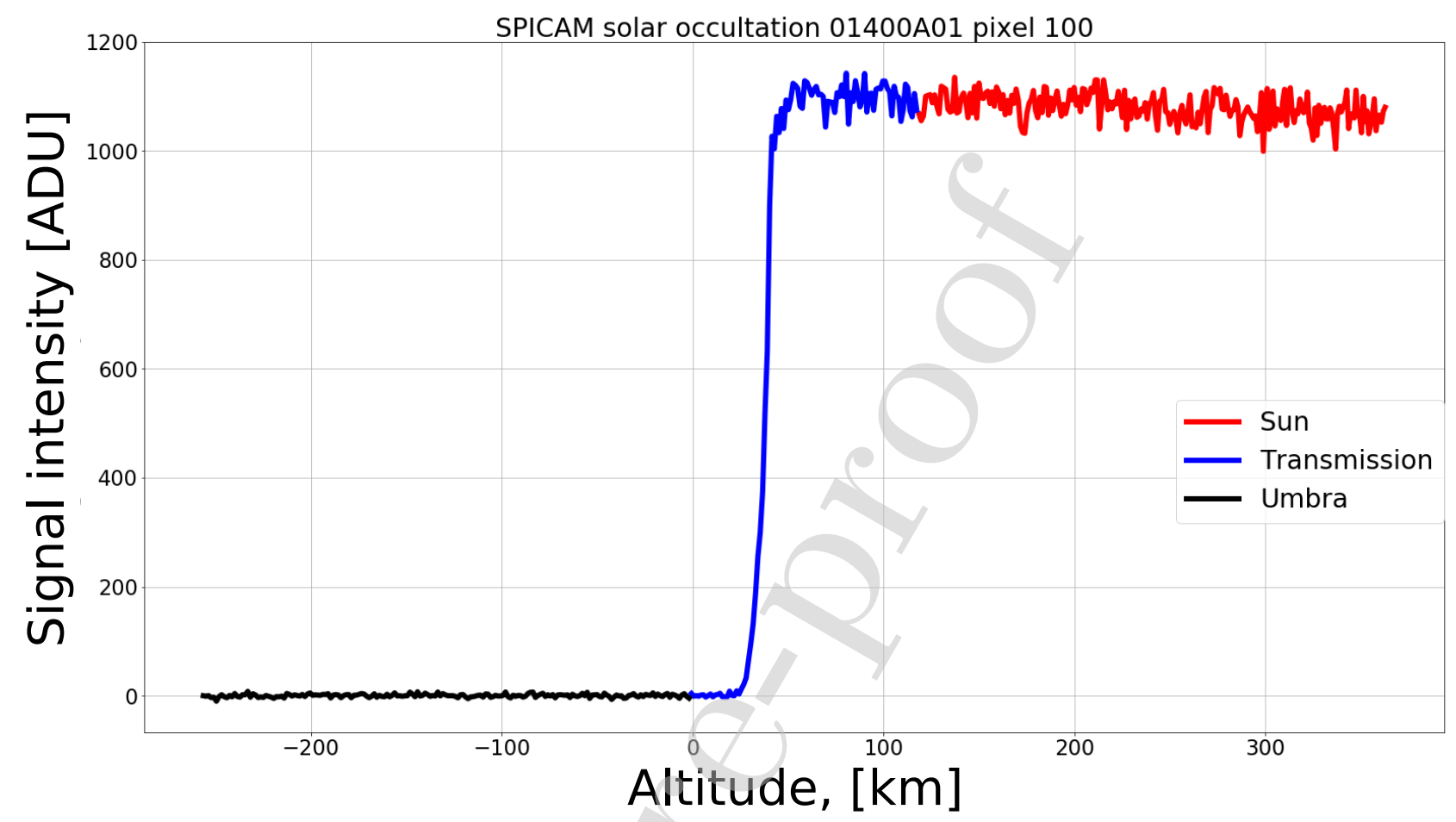

Figure 3: Example of intensity of the signal recorded on one pixel of the detector. The "Sun" region lies above 120 $\mathrm{km}$ (red), the "Transmission" region between 0 and $120 \mathrm{~km}$ (blue) and the "Umbra" region under about $15 \mathrm{~km}$ of tangent altitude (black).

\subsection{Transmittance estimation}

The spectra recorded during a solar occultation measurement can be separated in three regions represented on Figure 3:

- The "Sun" region: it contains solar spectra recorded when the LOS does not cross the atmosphere,

- The "Transmission" region: it contains atmospheric spectra recorded when the LOS crosses the atmosphere,

- The "Umbra" region: it contains the data recorded when all the light of the Sun has been absorbed or occulted by Mars. 
For the Martian atmosphere, and given the SNR of SPICAM-UV, we consider that the separation between the "Sun" and the "Transmission" region occurs at $120 \mathrm{~km}$ of tangent altitude.

The solar reference spectrum $S$ is computed by extrapolating, for each pixel, the intensity of the spectra recorded in the "Sun" region using a linear regression. Transmittances $T r$ are, then, computed by dividing the spectra of the "Transmission" region by the extrapolated solar reference spectrum $S$ at the same time, i.e. at the same tangent altitude (in occultation measurements, each spectrum has a particular time of measurement and tangent altitude and they are proportional or inversely proportional for egress or ingress measurement, respectively). The noise $\delta T r$ on the transmittances is calculated using the formula from Vandaele et al. (2013), and the SNR is the ratio of the transmittance $\operatorname{Tr}$ to the corresponding noise $\delta \operatorname{Tr}$ :

$$
\begin{array}{r}
\delta P(t)=\delta U+\sqrt{\operatorname{Tr}(t)}(\delta S-\delta U) \\
\delta \operatorname{Tr}(t)=\frac{\sqrt{\delta P(t)^{2}+\operatorname{Tr}(t)^{2} \delta S^{2}}}{S(t)} \\
S N R(t)=\frac{\operatorname{Tr}(t)}{\delta \operatorname{Tr}(t)}
\end{array}
$$

where $\delta \mathrm{S}$ and $\delta \mathrm{U}$ are the noise in the "Sun" region and in the "Umbra" region respectively. They are computed for each pixel by taking the standard deviation of the signal in the corresponding region. $\delta \mathrm{P}$ is the noise for the "Transmission" region in unit of ADU (Analog-to-Digital units).

In a perfect measurement, the LOS of the instrument does not move on the Sun, and the detector sensitivity remains constant, so that we would expect the signal to be constant in the "Sun" region within the noise. In practice, this is not always the case, and taking into account all the spectra recorded in the "Sun" region may not lead to the correct extrapolated solar spectra. To take into account a variation of the signal along the occultation, we use a simple linear regression on the signal of each pixel in the Sun region, in order to extrapolate a solar reference spectrum for each spectrum in the transmission region.

We have adapted the algorithm used for SOIR (Nevejans et al., 2006) on Venus Express and described in Trompet et al. (2016). This algorithm is based on the fact that we expect that the transmittances $\operatorname{Tr}$ will not deviate too much from 1.0 for the highest tangent altitudes, i.e. when the solar light is still too weakly absorbed to be seen on the spectra. Concretely, we expect that the estimated transmittances do not deviate further than $n$ times the values of the noise $\delta T r$ : 
$\operatorname{Tr}-n * \delta \operatorname{Tr}<1<\operatorname{Tr}+n * \delta \operatorname{Tr}$, where $n$ is in the range $[1,3]$.

The value $n$ is not fixed and a loop over that value has been added as the dataset can be rapidly treated. The value $n$ begins with the value of 1 and increases by step of 0.5 if the criteria (Eq. 1c) are not satisfied until the value of 3 .

During the acquisition of a spectrum, the signal is spread on several spatial lines of the detector. For SPICAM, the signal on these different lines are binned into five bands.

For this study, these five bands have been added up to enhance the SNR ratio of the calibrated spectra. Using the five bands, we noticed an increase of the mean SNR over the whole dataset of $30 \%$ with respect to the case where only the three middle bands were taken and of $67 \%$ with respect to the case where only the middle band was used.

\section{Model fields of atmospheric quantities}

We use the GEM-Mars three-dimensional General Circulation Model (GEM-Mars GCM) with online chemistry (meaning photolysis and reaction rates, production and loss rates are computed at each model integration step) for the atmospheric input profiles and to quantify the gradients across the terminator. The model includes gas-phase photochemistry (46 reactions in total), parameterizations for molecular diffusion, $\mathrm{CO}_{2}$ condensation/sublimation and pressure cycle, water cycle with cloud radiative feedbacks, non-condensable gas enrichment, and a dust lifting scheme for saltation and dust devils. The gas-phase species, dust and water ice particles are advected using the semi-Lagrangian dynamical core.

The photolysis and reaction rates are calculated at each model integration time step, and absorption by $\mathrm{CO}_{2}, \mathrm{O}_{2}, \mathrm{O}_{3}, \mathrm{H}_{2} \mathrm{O}$ and $\mathrm{H}_{2} \mathrm{O}_{2}$ along the line of sight as well as attenuation by dust and water ice are taken into account.

A detailed description and evaluation of the model can be found in Neary and Daerden (2018) with further information regarding the chemistry in Daerden et al. (2019).

To provide input profiles, the model was run at a horizontal resolution of $4^{\circ} \times 4^{\circ}$ (approximately $237 \mathrm{~km}$ longitudinal spacing at the equator) and 103 unevenly spaced vertical levels from the surface up to $\sim 150 \mathrm{~km}$. The spacing of levels near the surface is of the order of meters, increasing to $\sim 1$ $\mathrm{km}$ in the $10-50 \mathrm{~km}$ altitude range. A simulation was performed for a generic Mars year with average dust loading (not year specific) resulting from the dust-lifting scheme in the model with 
orbital parameters set to MY 28. The dynamical and chemical integration timestep was $1 / 48$ th of a Mars sol ( 30 minutes).

For the gradients, profiles of temperature and ozone were provided at each model timestep for the period 2 hours before until 2 hours after sunrise/sunset for each grid point the occultation traversed.

Below $25 \mathrm{~km}$, the gradients at both sunrise and sunset terminators are not large, but above this altitude, and in particular at $\sim 45 \mathrm{~km}$ near the equator, the density changes by several orders of magnitude across the terminator (See Fig. 4, and 6). At sunrise, photolysis of ozone occurs, as seen by its rapid depletion. There is some transport out of the boundary layer above $30 \mathrm{~km}$ during the afternoon. At sunset, photolysis stops and the ozone builds up due to the recombination of $\mathrm{O}$ and $\mathrm{O}_{2}$ in the presence of $\mathrm{CO}_{2}$. There is also a signature of downward transport during the night before sunrise. At southern high latitudes, during the winter, ozone variations at the terminator are almost negligible (Figure 5 and 6 left).

\section{Retrieval Method Description}

\subsection{Simulation}

All retrievals of the spectra have been performed using the ASIMUT-ALVL radiative code developed at IASB-BIRA (Vandaele et al., 2006). Initially developed for Earth observation missions (IASI and ACE-FTS, Vandenbussche et al. (2013)), the code was later adapted for planetary atmospheres, in particular for Venus (Vandaele et al., 2008) and Mars (Drummond et al., 2011; Robert et al., 2017, 2016; Vandaele et al., 2018). ASIMUT-ALVL is a modular program for radiative transfer calculations in planetary atmospheres. This code was developed with the objective to be as general as possible, accepting different instrument types (Fourier Transform Spectrometers, grating spectrometers, AOTF combined with an echelle grating) and different viewing geometries (nadir, ground-based, solar occultation/limb). Different radiation contributions are taken into account: direct Sun or reflected on the surface, surface emission and thermal atmospheric emission. Spectra can be simulated/retrieved in the IR, the visible, and in the UV as well. The surface is considered by default to be Lambertian, but a more complex treatment is possible. The determination of the radiation path through the atmosphere, i.e. the path followed by the radiation reaching the instrument, requires that the planet's curvature and refraction are taken into account. The 


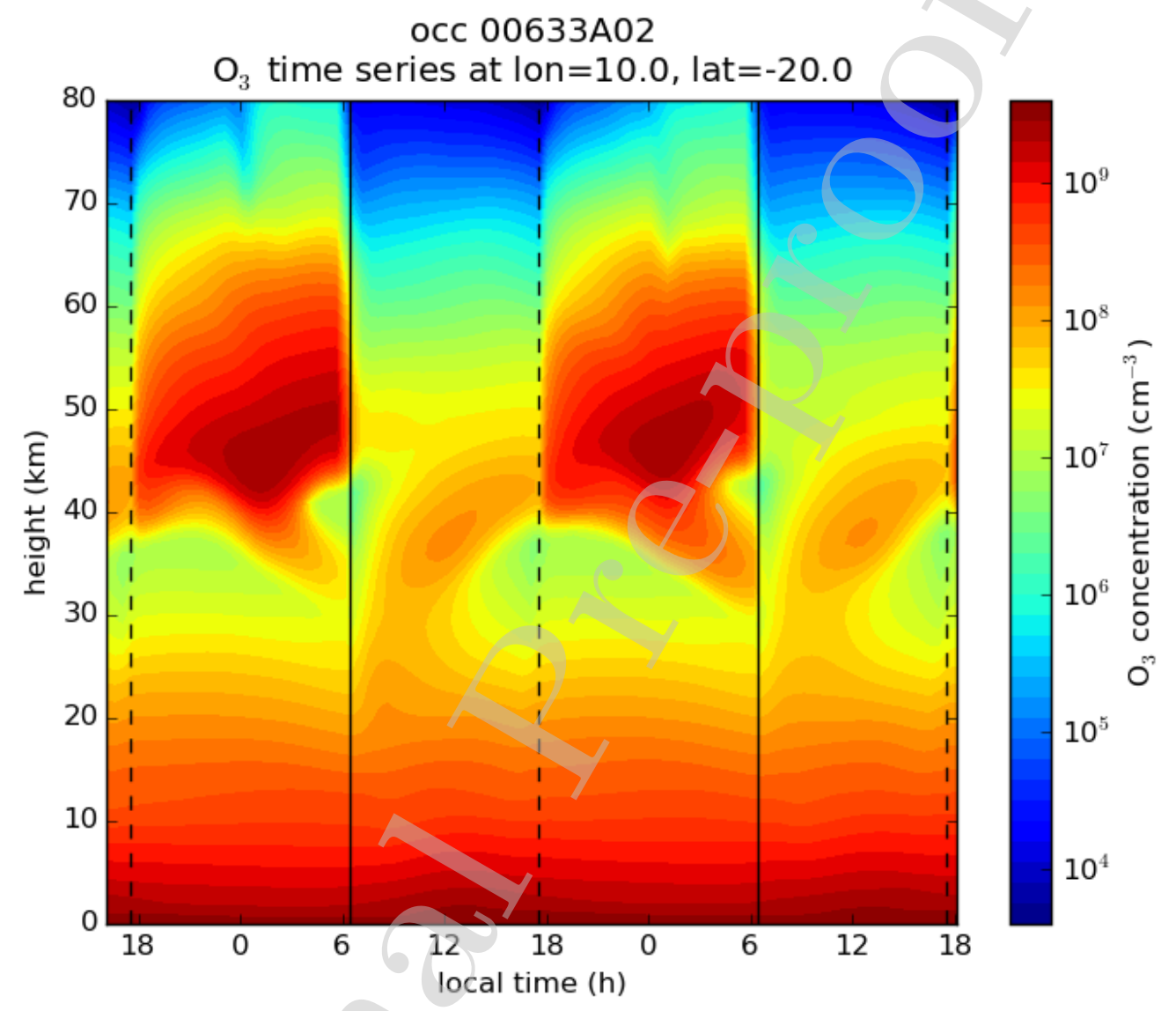

Figure 4: Time series profile of ozone concentration for one GCM model point at the time and location of the SPICAM occultation \#00633A02 (solar longitude: $62.3^{\circ}$ ). The solid (dotted) vertical line represents the sunrise (sunset) terminator. 


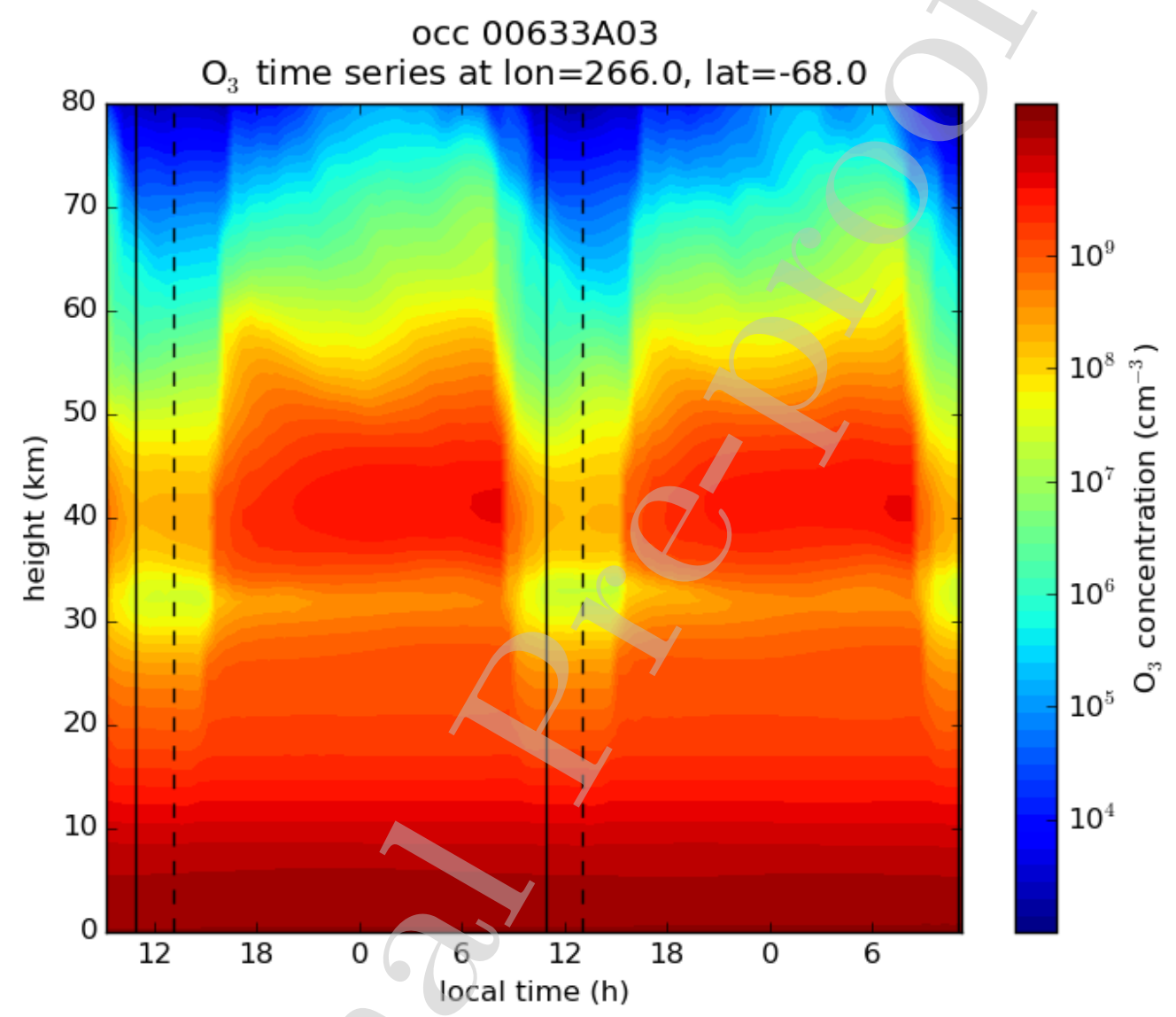

Figure 5: Time series profile of ozone concentration for one GCM model point at the time and location of the SPICAM occultation \#00633A03 (solar longitude: $62.3^{\circ}$ ). The solid (dotted) vertical line represents the sunrise (sunset) terminator. 
Sunrise

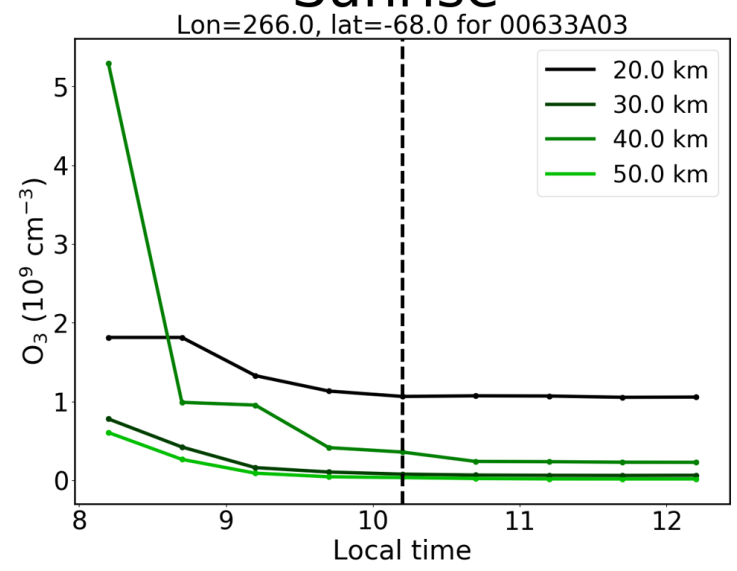

Sunset

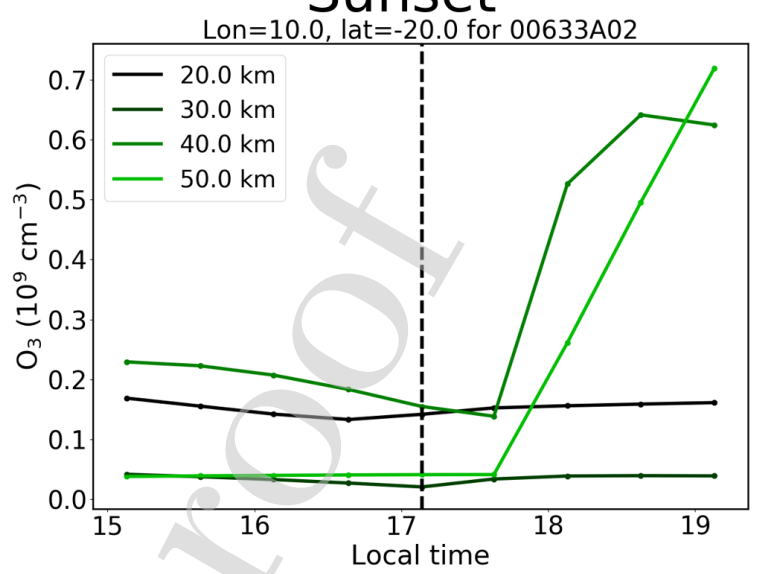

Figure 6: The diurnal variation in the model ozone at sunrise (occultation 00633A03) and at sunset (occultation 00633A02) for different altitudes. The dashed line shows the local time of the terminator.

model is based on the ray-tracing program FSCATM (Gallery et al., 1983). ASIMUT-ALVL has been coupled to SPHER/TMATRIX (Mishchenko and Travis, 1998) and LIDORT (Spurr, 2006) codes (Kochenova et al., 2011) to include the complete treatment of the scattering effects into the radiative transfer calculations. Aerosols are included in the ASIMUT-ALVL code, either through extinction only (ASIMUT) or considering their scattering properties (ALVL, through the call to LIDORT). The main retrieval module is based on the Optimal Estimation Method (Rodgers, 2000) coupled to the analytical calculation of the Jacobians. It enables simultaneous or sequential fitting of different parts of one or more spectra, in order to retrieve the surface temperature, columns or vertical profiles for molecular species or for aerosols and to fully characterize the outputs (averaging kernels, errors, DOFS, etc.). The model assumes a one-dimensional atmosphere, with all parameters varying only with the vertical variable, the altitude. More detailed information regarding the retrieval process and the uncertainties calculation can be found in Appendix A.

In this work, ASIMUT has been used without calling LIDORT since scattering by the atmosphere was considered negligible in solar occultation. All spectra of one occultation observation are analysed simultaneously (all transmittances at the various tangent heights) by ASIMUT, which derives one single $\mathrm{O}_{3}$ profile to best fit the ensemble of spectra. The atmosphere was structured in layers whose boundaries were the different tangent altitudes of the observation, adding layers of $1.5 \mathrm{~km}$ width above the highest tangent height up to $125.0 \mathrm{~km}$, which was considered the upper 
limit. Aerosols were not taken in account into the retrieval procedure. ASIMUT enables the user to fit the baseline spectrum. By configuring this additional fit, impact due to the uncertainties concerning aerosols could be reduced.

The equation describing the radiative transfer through the atmosphere (when no scattering is present) can be written as:

$$
I(\nu)=I_{0}(\nu) e^{-\tau(\nu, 0, z)}+\int_{0}^{z} B(\nu, T(s)) \alpha(\nu, s) e^{-\tau(\nu, 0, z)} d s
$$

where $I_{0}$ represents the light intensity at the starting point of the ray path situated at the distance $\mathrm{z}$ from the observer, $\alpha(\nu, s)$ is the absorption coefficient, $B(\nu, T)$ is the Planck function, and

$$
\tau\left(\nu, s_{1}, s_{2}\right)=\int_{s_{1}}^{s_{2}} \alpha(\nu, s) d s
$$

is the optical depth along the path between the points $s_{1}$ and $s_{2}$. The integration in Eq. 2 occurs along the LOS. The ray tracing (i.e. the determination of the atmosphere characteristics along the LOS) is done by integrating the temperature, the pressure, the total density, and the partial densities of all atmospheric constituents in the Curtis-Godson approximation (Goody, 1952; Godson, 1953). Under this approximation the effective pressure $\left(P^{\star}\right)$, the temperature $\left(T^{\star}\right)$, and the density of species $k\left(N_{k}^{\star}\right)$ needed to calculate the optical depth in a layer can be obtained by:

$$
\begin{aligned}
P^{\star} & =\frac{\int P \cdot \rho \cdot d s}{\int \rho \cdot d s} \\
T^{\star} & =\frac{\int T \cdot \rho \cdot d s}{\int \rho \cdot d s} \\
N_{k}^{\star} & =\frac{\int N_{k} \cdot \rho \cdot d s}{\int \rho \cdot d s}
\end{aligned}
$$

where $\rho$ is the total air density, $P, T$, and $N_{k}$ are respectively the pressure, the temperature, and the density of species $k$ within the layer, and $d s$ is the elementary path length through the layer on which the integration is done. The calculation of the integral is performed on a sub-grid of layers separated by $200 \mathrm{~m}$.

The optical depth in each of the layers are calculated considering absorption/extinction by $\mathrm{O}_{3}$, $\mathrm{CO}_{2}$ and Rayleigh scattering. For $\mathrm{CO}_{2}$, the cross-sections from Huestis and Berkowitz (2010) have 
been selected since they cover a wide spectral interval at relatively high resolution. They are in very good agreement with the data of Parkinson et al. (2003) obtained at $295 \mathrm{~K} . ~_{3}$ cross-sections have been built around the temperature dependent data sets of Serdyuchenko et al. (2014), extending the cross sections towards the shorter wavelength by using either the Reims data set (Brion et al., 1993; Daumont et al., 1992; Malicet et al., 1995) or the JPL compilation (Sander et al., 2011) depending on the available temperatures. From these data, a temperature dependent cross-section was built for $\mathrm{O}_{3}$ which was used to calculate the optical depth at the temperature of the layer. Rayleigh scattering was included only as an extinction (no true scattering effects considered) using the data from Sneep and Ubachs (2005). Transmittances corresponding to each sounded altitude were fitted by considering the absorption of all layers traversed by the LOS of the instrument. They were then convolved to correspond to the resolution of the SPICAM instrument $(0.51 \mathrm{~nm})$.

\subsection{Gradients as variation along the $L O S$}

The treatment of solar occultation observation has been improved in this work by considering gradients and variations of the density and temperature along the LOS and in particular at the terminator. Three different gradients can be considered: (1) Temperature gradients across the terminator; (2) (Total) density gradients across the terminator; and (3) Density variations along the LOS. These gradients will have an impact on the ray tracing procedure (more accurate determination of the temperature, pressure, and densities within the layers of the atmosphere) and on the optical depth of the species, since they depend on the temperature and the partial densities of the species.

The correction for the gradients consists of introducing a correction which depends on the top and bottom altitudes of the layer, which in fact correspond to slightly different Local Solar Times (LST $T_{\text {bottom }}$ and $L S T_{\text {top }}$, see Figure 7). Two calculations need to be done for the Day and Night sides respectively. Indeed, at the dawn terminator, the local solar time increases towards the day side and decreases towards the night side. At dusk, this behaviour reverses..

$$
\begin{aligned}
& L S T_{b / t}^{N}=L S T_{\text {terminator }}-f\left(A_{b / t}^{z}\right) \\
& L S T_{b / t}^{D}=L S T_{\text {terminator }}+f\left(A_{b / t}^{z}\right)
\end{aligned}
$$




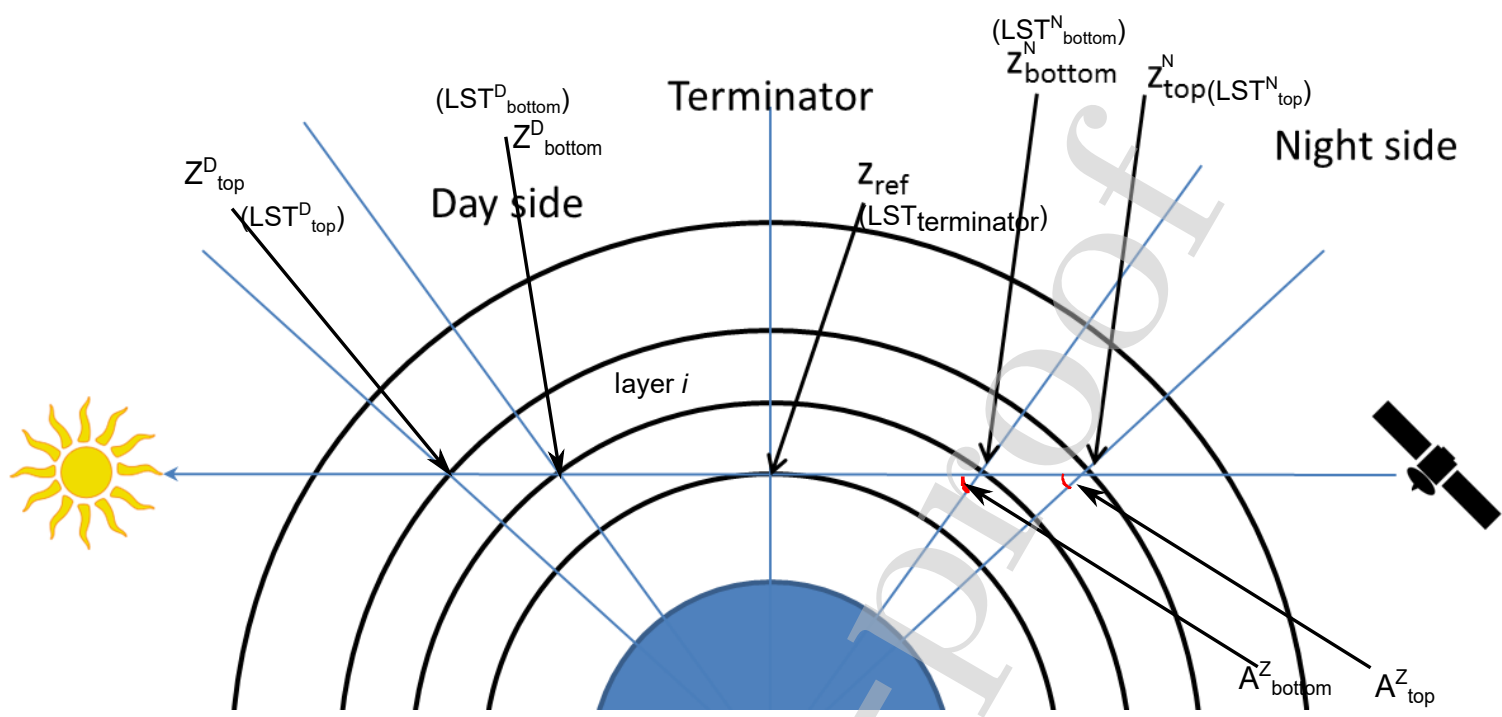

Figure 7: Geometry of a solar occultation; definition of the 'Day' and 'Night' sides.

line joining the point along the LOS at altitude $z$ and the center of the planet and $f$ is a function describing the link between $A^{z}$ and time defined by the geometry of the observation.

In the following, we will introduce 'Day' and 'Night' densities or temperatures $\left(T_{i}^{\star D}, T_{i}^{\star N}\right.$, $N_{k, i}^{\star D}, N_{k, i}^{\star N}$, for species $k$ and layer $i$ ); these will in fact refer respectively to 'after' and 'before' the terminator (see Figure 7).

The different gradients are implemented in the following way. When the user asks to take the temperature gradient into account, two optical depths are calculated for each layer, corresponding to the two 'Day' and 'Night' temperatures. These temperatures are calculated using Curtis-Godson approximation (Eq. 5), where the temperature in the layer is interpolated from the GEM-Mars simulation data at the LST corrected using Eq. 7-8. Note that the calculation of the 'Night' optical depth is done only if the two temperatures differ by at least a minimum value which can be specified by the user (default value set to $2.0 \mathrm{~K}$, minimal value= $0.1 \mathrm{~K}$ ). Then, the total optical depth $(O D)$ for the layer $i$ and the species $k$ is the average of the 'Day' and 'Night' side contributions:

$$
O D_{i}^{k}=\frac{\left[O D_{i}^{k}\left(T_{i}^{\star D}\right) \times N_{k, i}^{\star D}+O D_{i}^{k}\left(T_{i}^{\star N}\right) \times N_{k, i}^{\star N}\right]}{2}
$$


When the user asks to take into account gradients or variations of densities (total density or density of a specific species, such as $\mathrm{O}_{3}$ ), the densities of the 'Day' and 'Night' side of the terminator are deduced using the Curtis-Godson approximation (Eq. 6), based on interpolated values of the densities from GEM-Mars simulation data at the LST corrected using Eq. 7-8

\subsection{Fit strategy}

Several input parameters are needed to constrain the retrieval: a priori vertical profiles of the different species included $\left(\mathrm{CO}_{2}\right.$ and $\left.\mathrm{O}_{3}\right)$ as well as of the temperature and pressure of the atmosphere. All a priori information is taken from the GEM-Mars simulations.

We assumed as an a priori nominal ozone profile the global average ozone VMR from GEMMars; i.e. average of all profiles at all Lat/Lon and seasons for one year (MY27). The mean and standard deviation of the ozone volume mixing ratio (VMR), in addition to mean temperature, pressure, and altitude, were derived from the GEM-Mars output of 48 time-steps per day and one day per $10 \mathrm{Ls}$, for a total of 1728 individual time-steps. The MOLA topographical surface height (Smith et al., 1999) was added to each vertical profile, so that the altitude coordinates are relative to the MGM1025 Mars areoid (Lemoine et al., 2001), and then each individual vertical profile was averaged into $1 \mathrm{~km}$ bins from $-8 \mathrm{~km}$ to $165 \mathrm{~km}$. The vertical profiles were weighted by spherical surface area of the latitude/longitude grid to not oversample the poles due to the regular grid, as well as weighted by the vertical extent of each altitude point to not oversample the near surface profiles due to the adaptive vertical grid. A more detailed description of this derivation, as well as the effects of different methods of averaging and weighting on the a priori profiles, will be discussed in a separate article in preparation (Erwin et al., 2018).

In a typical retrieval of an (solar) occultation observation, the altitudes at which the $\mathrm{O}_{3}$ densities are retrieved are the different tangent heights of the different transmittances.

\section{Ozone retrievals assuming a spherically symmetrical atmosphere}

As a first step, we performed the retrieval of ozone assuming a spherically symmetrical atmosphere. Figure 1 displays transmission spectra at different altitudes (see colorbar) compared to simulated spectra (black solid line) for occultation \#00633A02. In addition to the retrieved ozone profiles, ASIMUT produces several metrics that can be used to assess the retrievals. The averaging kernels are one of them. Averaging kernels allow to study how the information content is 


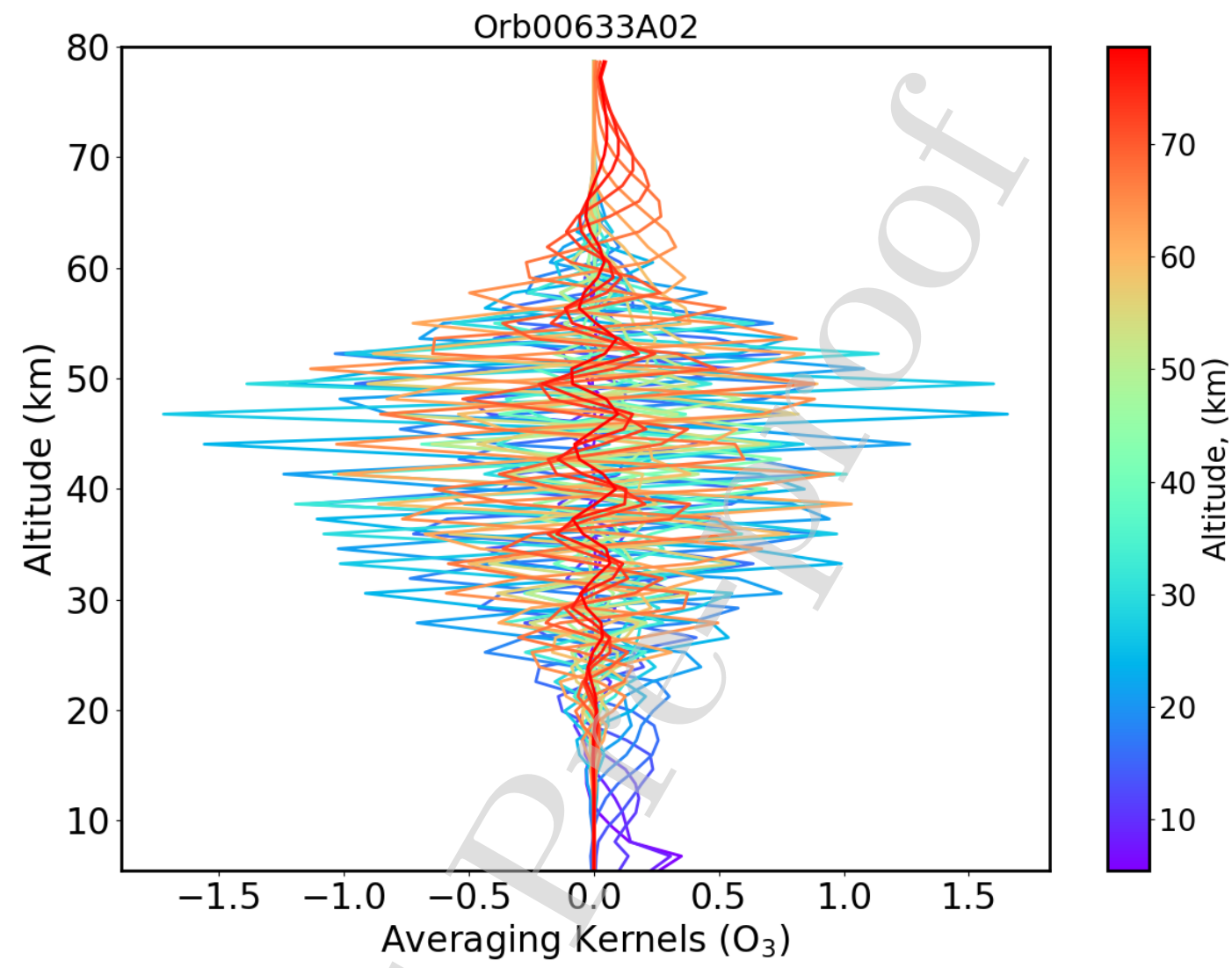

Figure 8: Averaging kernels for occultation \#00633A02.

distributed in the retrieved profiles. They provide an estimation of the vertical sensitivity of the retrieval and peak at the altitude of maximum sensitivity. Figure 8 shows the averaging kernel for occultation \#00633A02. From this plot it is evident that the information content is constrained to the altitude range $\sim 20-60 \mathrm{~km}$. Below this altitude, the horizontal opacity of the dust limits the measurements.

We assessed the sensitivity of the ASIMUT ozone profile retrieval algorithm to a number of a priori assumptions. We studied the impact of the a priori ozone profiles, and of the initial temperature profile on the retrieved ozone profile, as described in more details below. 


\subsection{Sensitivity to the ozone a priori profile}

We tested the dependency of ozone retrievals to the choice of the ozone a priori profile. We used three profiles as a priori obtained by multiplying the nominal a priori ozone profile by different factors. In Figure 9 (top) we present two tests respectively for occultation \#00633A02 at sunset and occultation \#00633A03 at sunrise. Bottom panels in Figure 9 are similar, but this time we used as a priori profiles constant VMR profiles. In all cases, the retrieved profiles converge within the expected uncertainty, except at low altitudes during sunrise.

\subsection{Sensitivity to the temperature profile}

We tested the sensitivity of the retrieved ozone profiles to the initial choice of temperature profile. We used as nominal temperature profile the global/temporal average temperature from GEM-Mars. We then tested two other temperature profiles obtained by adding $\pm 15 \mathrm{~K}$ to the nominal profile. This value lies within the uncertainty on temperature in GEM-Mars (Neary and Daerden, 2018). We found a percentage change in the ozone profiles obtained using the two temperature profiles (blue and red lines in Figure 10) smaller than $25 \%$ at $42 \mathrm{~km}$.

\subsection{Error analysis}

Errors on the retrieved ozone result from random noise in the measurements and they are quantified in the inversion method. These random errors are $<5 \%$ between 30 and $40 \mathrm{~km} ;<10 \%$ below and above these altitudes and they reach a maximum value of $40 \%$ at the upper and lower boundaries. Another source of error on the retrieval of ozone profiles comes from the choice of $a$ priori $\mathrm{O}_{3}$ vmr profile. The retrieved ozone is particularly stable against a change in the a priori $\mathrm{O}_{3}$ vmr profile (Figure 9). However, uncertainties are mainly dominated by errors due to the initial temperature profile. A change in the input temperature profile produces a maximum difference of $\pm 25 \%$ on ozone at $42 \mathrm{~km}$ (Figure 10$)$.

6. Ozone retrievals assuming concentration and temperature gradients around the terminator

\subsection{Sensitivity to temperature gradients}

We tested the sensitivity of retrievals to temperature and total density gradients provided by the GEM-Mars, described in section 3. As mentioned in Section 4.2, if the difference in dayside 
Sunrise

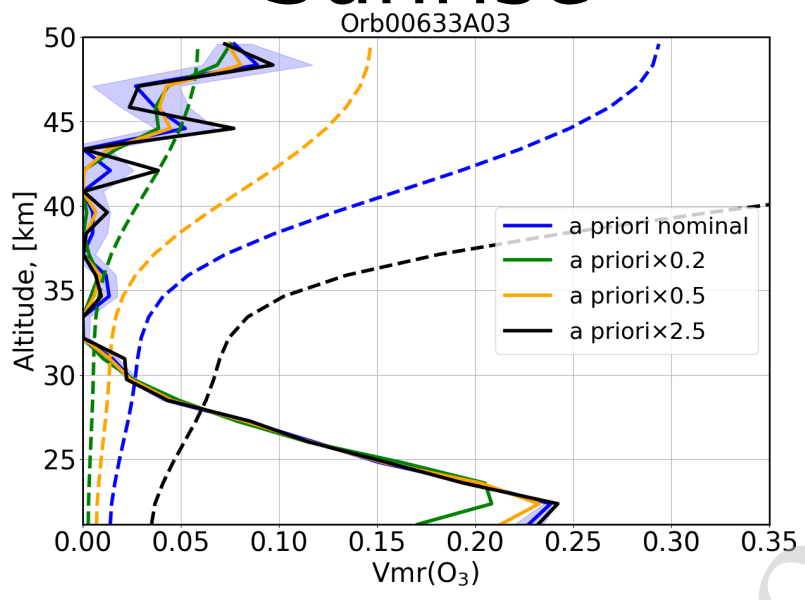

Orb00633A03

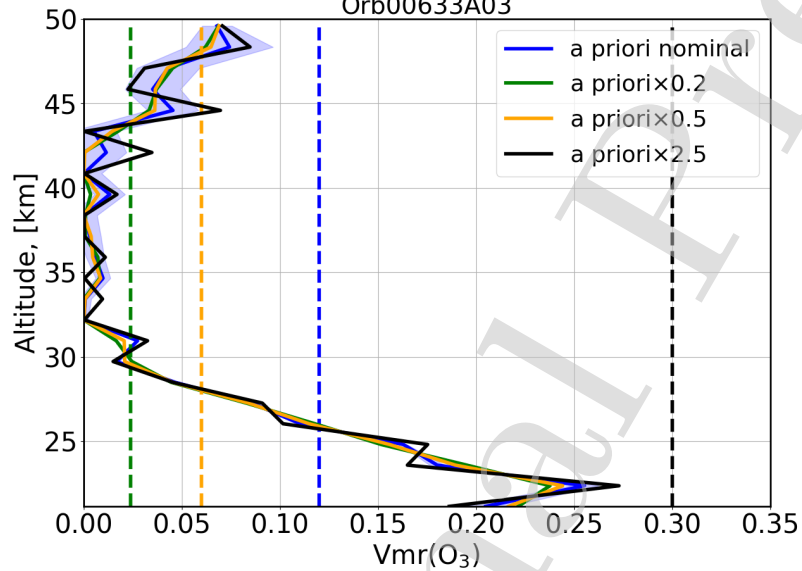

Sunset

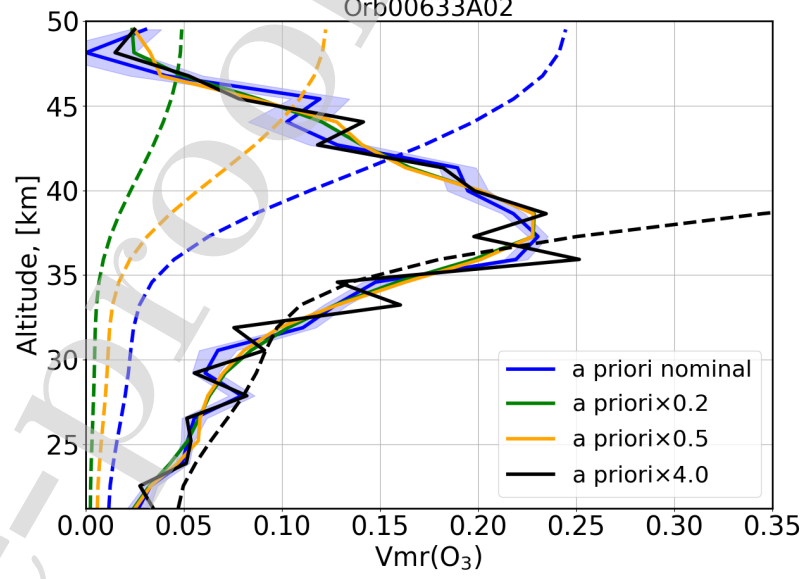

Orb00633A02

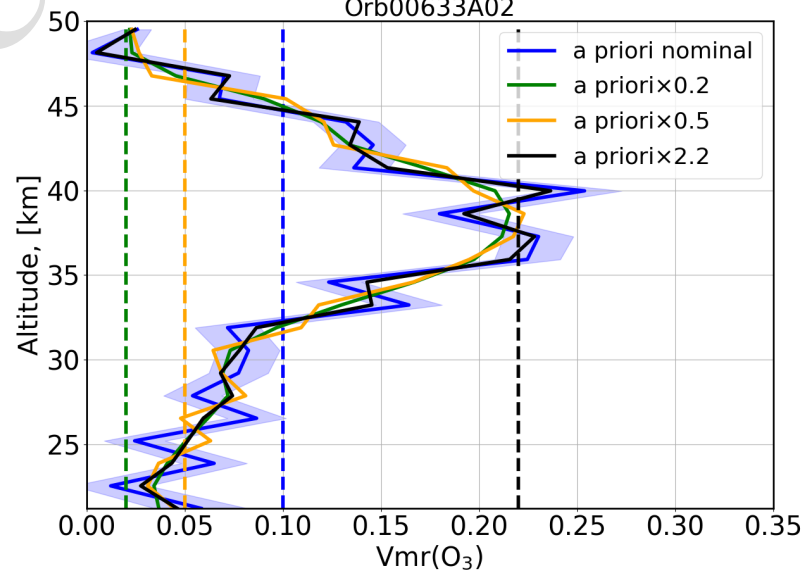

Figure 9: Retrieved ozone profiles [ppm] (solid lines), starting from different first-guess profiles (dashed lines), for occultation \#00633A03 (left panels) at sunrise and occultation \#00633A02 (right panels) at sunset. Top panels use a priori profiles derived from the nominal a priori profile (dashed lines). Bottom panels use constant profiles as a priori. 


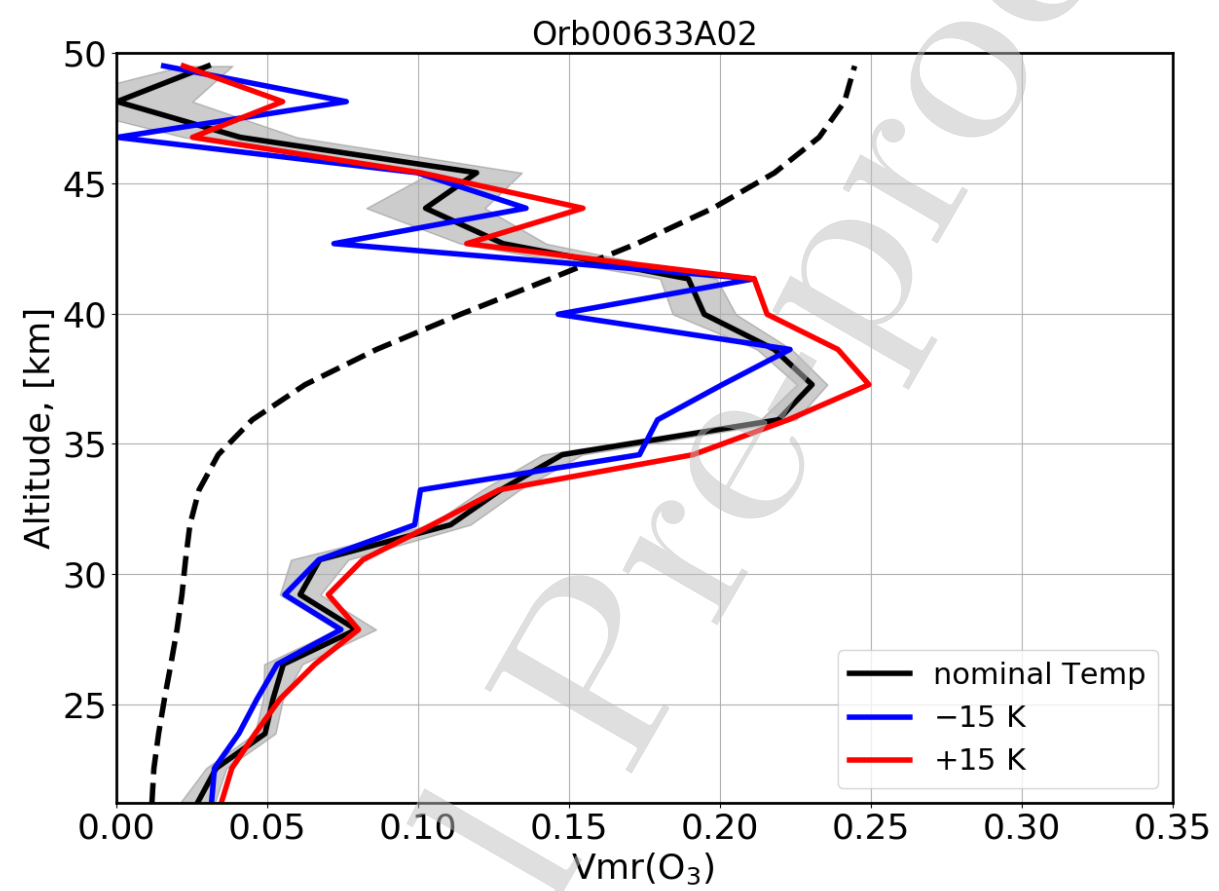

Figure 10: Retrieved ozone profiles [ppm] obtained assuming different first-guess temperatures profiles: (black) nominal temperature; (blue) nominal-15 K; and (red) nominal+15 K. The gray area marks the uncertainty of the retrieved profile. For clarity, only the uncertainty for the nominal profile is shown, similar values are found for the other retrievals. The a priori profile (dashed line) is also shown. 
and nightside temperatures exceeds a threshold, different densities are used for the day and night sides. This threshold is configurable. The default value is set to $2.0 \mathrm{~K}$, we tested in addition a minimal value of $0.1 \mathrm{~K}$. Moreover, we multiplied the GEM-Mars gradients by a factor of 2 and 5. Temperature gradients do not have any impact on the retrievals of ozone (figures are not shown here). This can be explained by the small temperature dependence of the $\mathrm{O}_{3}$ cross sections. Nevertheless, we included temperature gradients in the retrieval process.

\subsection{Sensitivity to $\mathrm{O}_{3}$ gradients}

We investigated the impact of taking into account the variations of ozone concentrations along the LOS at the day/night terminator. As input, we provided the ozone gradients calculated by the GEM-Mars (see section 3). The differences in the model between the ozone variations for sunset and sunrise conditions, as well as for different locations (see Figures 4 and 5), suggest that the effects of gradients on the retrievals should change for different occultations. The steeper gradient for the selected sunset occultations at low latitudes indicates the impact of gradients will be stronger for these occultations compared to sunrise data (Fig. 6).

Figures 11 and 12 show retrieved ozone profiles for different occultations respectively at sunset and sunrise. Ozone profiles (solid red line) derived using GEM-Mars gradients are compared to profiles obtained assuming a spherically symmetrical atmosphere (blue dashed line). The insert panels show the vmr differences in percent between the two retrievals. At sunset (Figure 11), retrievals show an ozone layer located in the altitude range $35-50 \mathrm{~km}$. The inclusion of gradients in the retrieval method results in a $<20 \%$ reduction in ozone mixing ratio for sunset condition. Except for occultation \#00584A02, the impact of retrievals lies within the error bar. The rapid variations observed for occultation \#00655A01 are due to the retrieval procedure.

At sunrise (Figure 12), profiles show the presence of an ozone layer located near the surface, the top of which is located at altitudes below $30 \mathrm{~km}$. The impact of gradients on retrievals at sunrise is negligible. This behavior can be explained by the specific locations of sunrise occultations. In fact, as shown in Figure 5, the day length is much shorter compared to the night at these latitudes and season and the ozone gradient is not very sharp.

In order to test the sensitivity of the retrievals on the initial ozone gradient, we multiplied the difference between day and night ozone along the LOS (provided by GEM-Mars) by factors of 2 and 3. Factors 1,2 , and 3 produce a percentage change with respect to the nominal profile of 

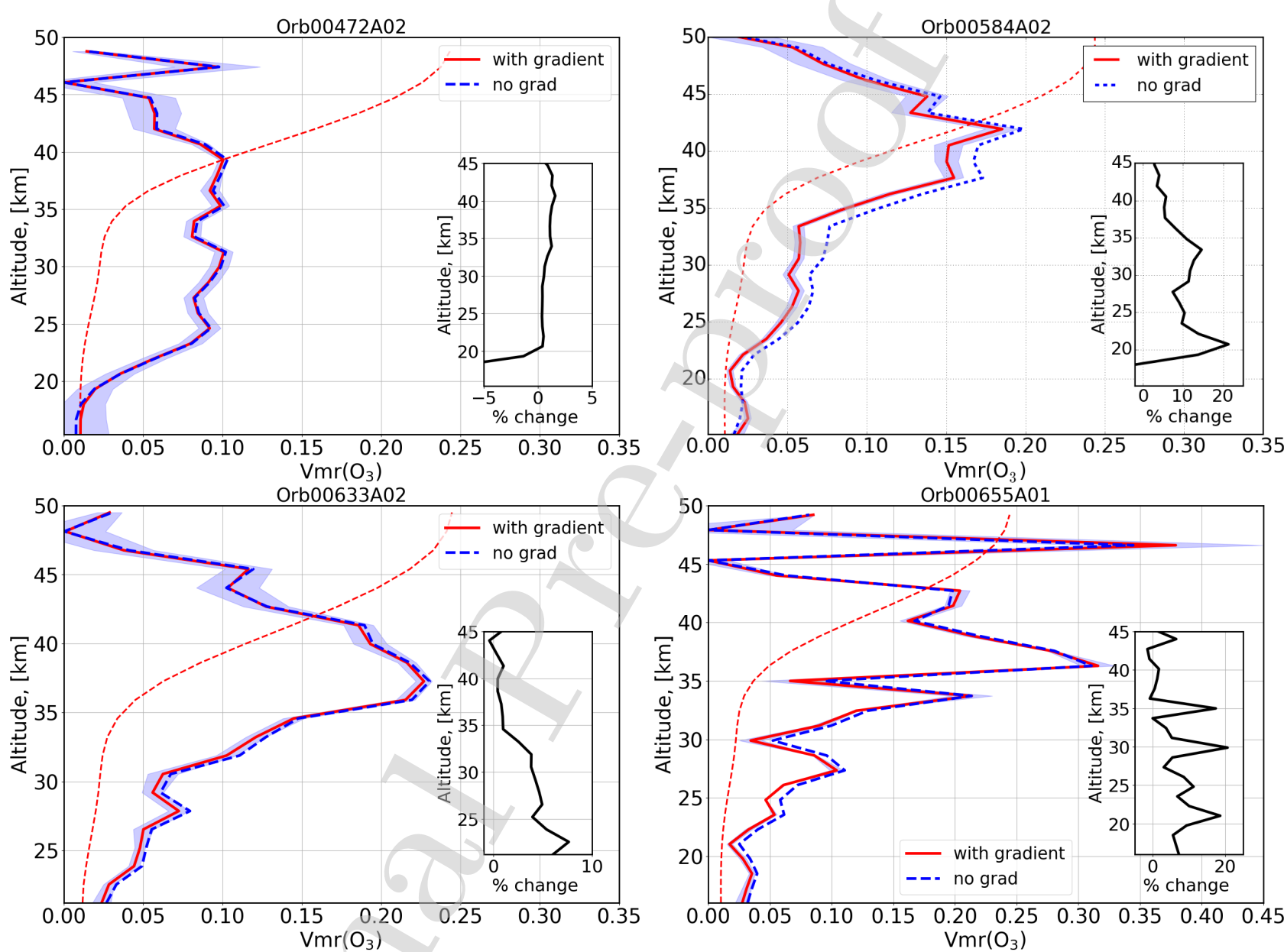

Figure 11: Retrieved ozone profiles [ppm] for different occultations at sunset derived using GEM-Mars gradients (red solid lines) compared to profiles retrieved assuming a spherically symmetrical atmosphere (blue dashed lines). The a priori profile used for the retrieval is also shown (red dashed line). The insert panel shows the vmr difference in percent between the two retrievals. 

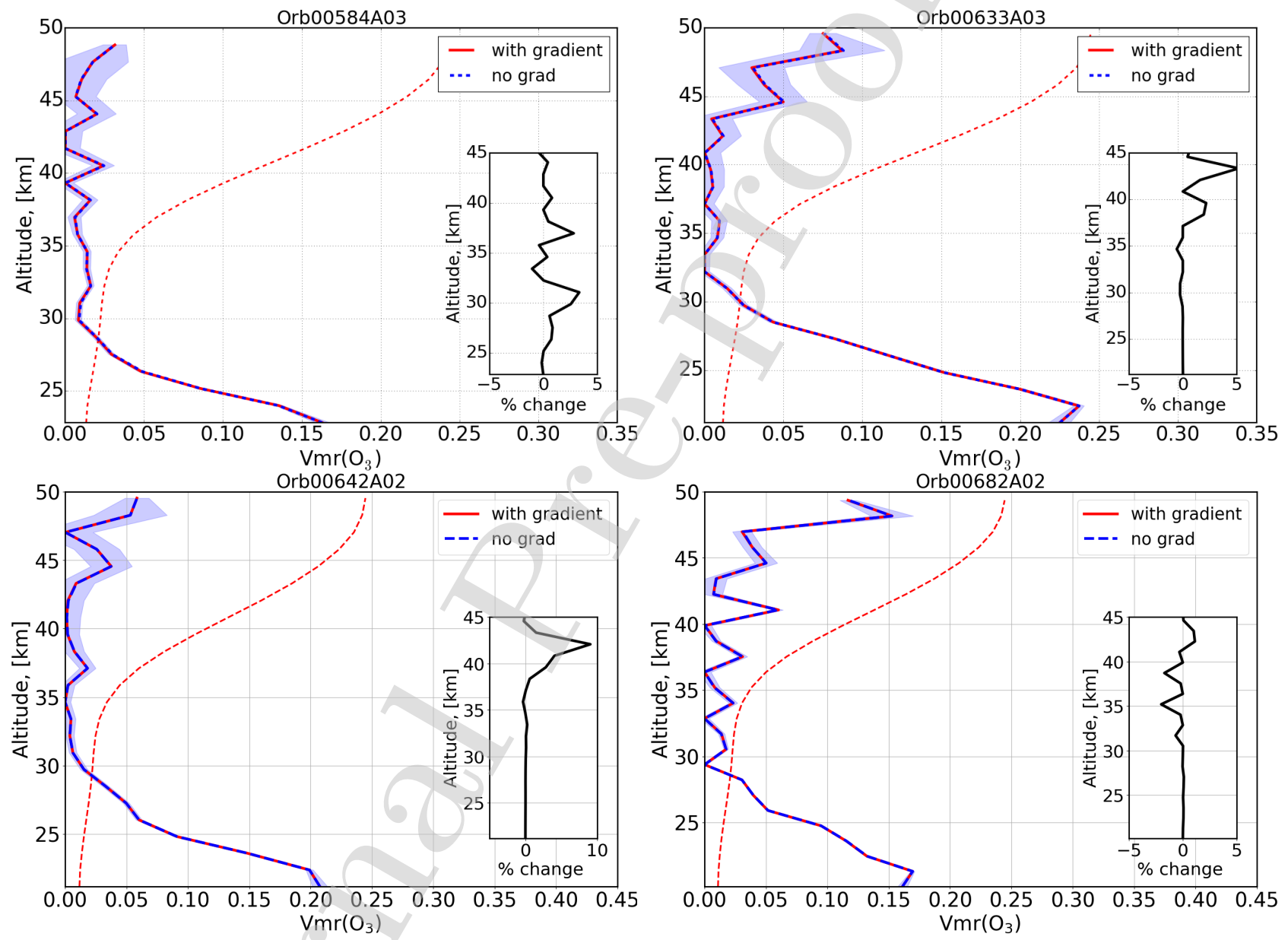

Figure 12: As in Fig. 11 but for occultations acquired at sunrise. 
respectively: $<7 \%,<30 \%$, and $<59 \%$ at altitudes below $30 \mathrm{~km}$ (See Fig. 13).

The effect of gradients on the retrievals depends on the inputs gradients provided by the photochemical model, in our case GEM-Mars. The model gradients, moreover, strongly depend on the latitude, altitude, and season of the occultations, since ozone is dependent on all these factors.

\section{Comparison to a different retrieval strategy}

In order to validate different retrieval methods, we compared our results with the profiles of ozone from SPICAM solar occultations analysed by Määttänen et al. (submitted to Icarus, 2019) (LATMOS retrievals from now on). It is important to notice that the spectral fitting strategy for LATMOS retrievals is different from the one applied in this study: LATMOS retrievals result in profiles of concentrations of ozone integrated along the LOS (slant profiles). ASIMUT provides both vertical and slant profiles. To compare the results obtained from the two methods, in this section we are therefore showing ASIMUT slant retrievals.

The data analysis method for the LATMOS retrievals are discussed in Quémerais et al. (2006); Montmessin et al. (2006); Määttänen et al. (2013, submitted to Icarus, 2019) and are only briefly summarized here. The transmission spectra are calculated by averaging the solar spectrum measured above $120 \mathrm{~km}$, and then dividing all the spectra by this reference spectrum. Only spectra void of spurious high-gain peaks or oscillations caused by the MARSIS radar antennae are used in the procedure (see Määttänen et al. (2013)). To obtain the LOS ozone columns, the transmission spectra are fitted with a model based on the Beer-Lambert (BL) law that in this case describes the total absorption on the LOS by gases $\left(\mathrm{CO}_{2}, \mathrm{O}_{3}\right)$ and by aerosols (using the so-called $\alpha$-model: O'Neill and Royer (1993); Dubovik et al. (2000)). The BL model does not include any assumptions of gradients along the line of sight, since it simply describes the transmissions as the result of the sum of the extinctions caused by the total concentrations of species on the LOS. The BL model is fitted to the transmissions by using a Levenberg-Marquardt method (IDL routine MPFIT, Markwardt (2009)) and adjusting simultaneously the four unknowns: total concentrations of $\mathrm{CO}_{2}$ and $\mathrm{O}_{3}$, the dust optical depth and the $\alpha$ coefficient. As the fitting is started from the top of the atmosphere (transmission is essentially equal to one, so no absorption is expected) the a priori values for $\mathrm{O}_{3}$ and dust are started from a very small value (practically zero) at the top of the atmosphere. Once the fitting procedure finds positive values for these variables, the fitting for each subsequent layer starts with the value of the previous layer as a first guess. Since the Sun is quite dim in the 


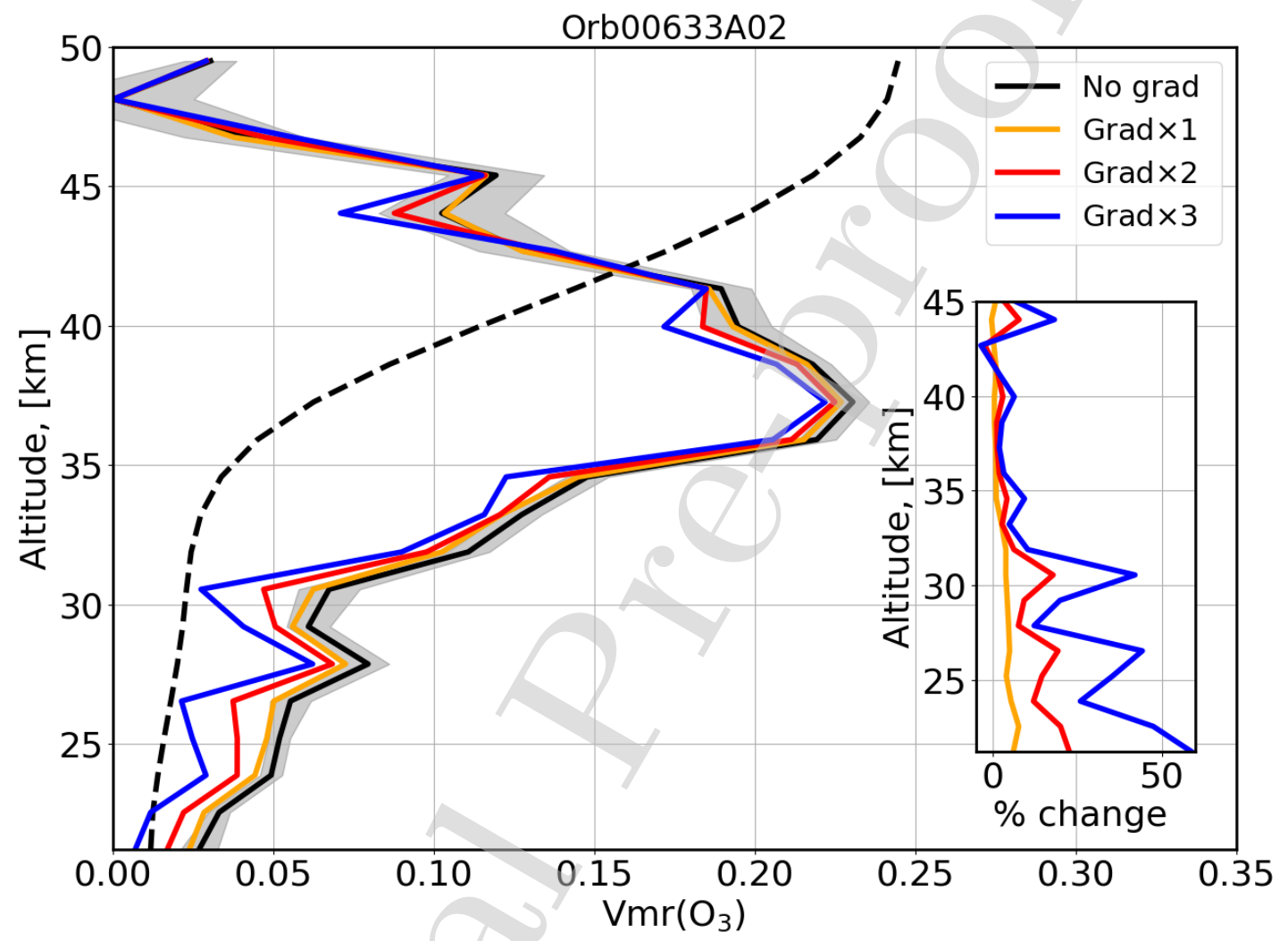

Figure 13: Retrieved ozone profiles [ppm] for occultation \#0633A02 derived using GEM-Mars gradients compared to the profile retrieved assuming a spherically symmetrical atmosphere (black line). GEM-Mars gradients were multiplied by different factors: 1 (yellow line), 2 (red line), and 3 (blue line). The a priori profile used for the retrieval is also shown (black dashed line). The insert panel shows the VMR difference in percent between the retrievals. 
$\mathrm{UV}$, the transmission spectra are very noisy within the $\mathrm{CO}_{2}$ absorption band below $200 \mathrm{~nm}$, often preventing the fitting routine from converging. We improved the $\mathrm{CO}_{2}$ fits significantly by defining the a priori for $\mathrm{CO}_{2}$ from profiles of the Mars Climate Database (MCD v4.3, Millour et al. (2008); see details in Määttänen et al. (2013)). The fitting provides LOS column concentrations of $\mathrm{CO}_{2}$ and $\mathrm{O}_{3}$, and LOS aerosol optical depth and a value for $\alpha$, and the corresponding uncertainties (see Määttänen et al. (2013) for details on the error estimation).

Figure 14 displays the comparison between ozone slant densities for three occultations at sunrise and sunset. Different colors correspond respectively to: (black) ASIMUT retrievals assuming a spherically symmetrical atmosphere; (red) ASIMUT retrievals including GEM-Mars gradients; and (orange) LATMOS retrievals assuming a spherically symmetrical atmosphere. The perfect agreement between ASIMUT retrievals assuming a spherically symmetrical atmosphere and ASIMUT retrievals including GEM-Mars gradients was expected, since gradients should not impact the LOS optical thickness. ASIMUT and LATMOS retrievals are in very good agreement. Differences, especially for sunset occultations, may be explained by different a priori inputs.

\section{Summary}

Rapid changes in the species concentration at the day-night terminator driven by differences in the solar illumination may cause asymmetries along the LOS of a solar occultation experiment that need to be taken into account in the retrieval process. In the present manuscript, we applied an improved retrieval scheme that handles concentration gradients along the LOS to the retrieval of ozone from SPICAM/MEx solar occultations. We used the GEM-Mars three-dimensional General Circulation Model to quantify the input gradients across the terminator for our retrievals. Our model results strongly depend on the latitude, altitude, and season of the occultations, since ozone is affected by all these factors. Ozone does not show strong variations with solar zenith angle (local solar time) at altitudes below $25 \mathrm{~km}$. Above this altitude, especially around $\sim 45 \mathrm{~km}$ near the equator, the density changes by several orders of magnitude across the terminator. In addition, near the equator, differences between sunrise and sunset variation in ozone concentration are evident and they can be explained by the ozone photochemistry. In the high latitude southern hemisphere, during the winter, ozone variations at the terminator are almost negligible.

The impact of gradients on the retrievals strongly follows the GCM model results. Uncertainties in the model ozone diurnal variations may affect the corrections to the retrieved profile. All selected 

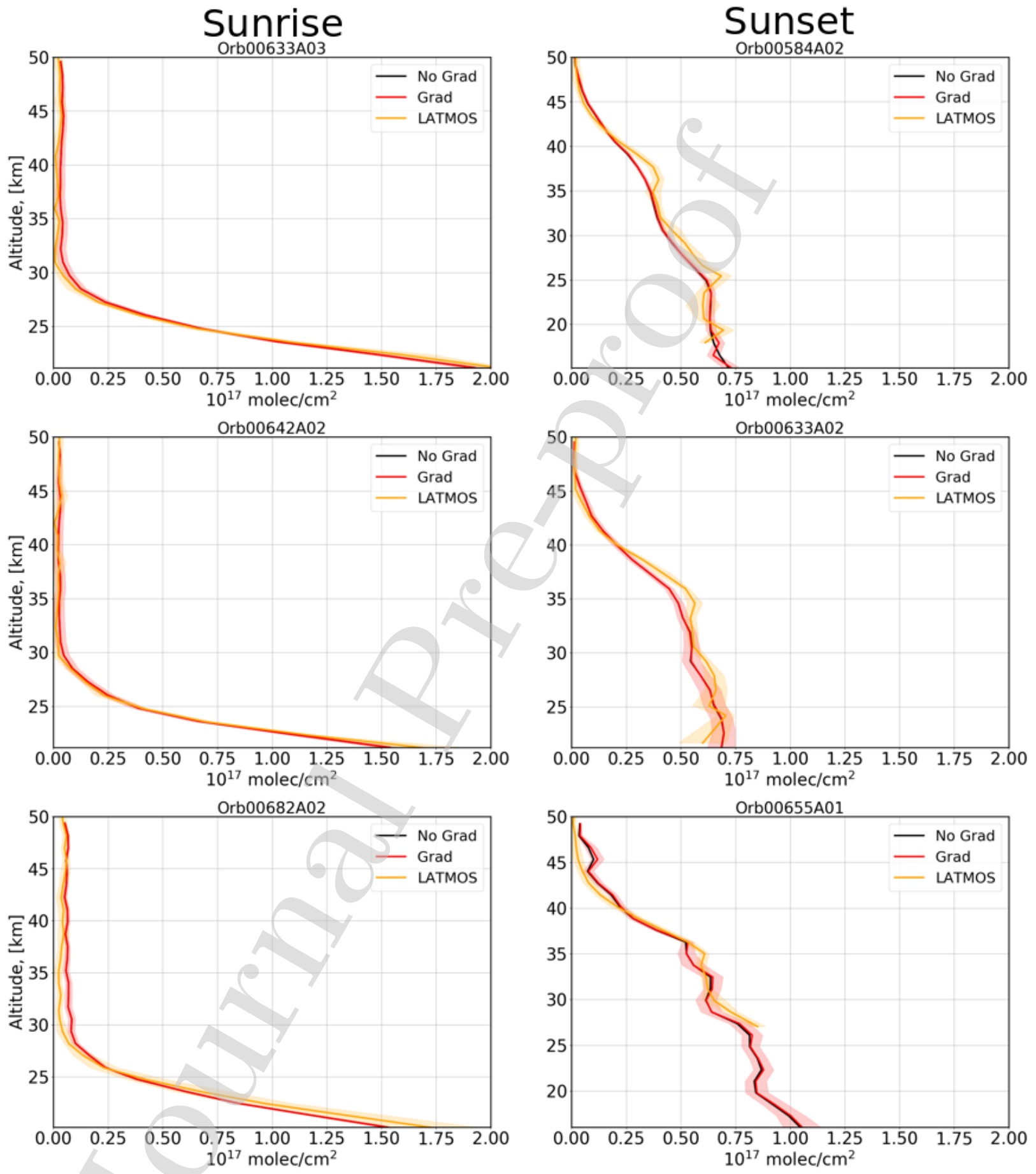

Figure 14: Examples of retrieved ozone slant densities derived using GEM-Mars gradients (red lines) compared to profiles derived at LATMOS (orange lines). ASIMUT profile retrieved assuming a spherically symmetrical atmosphere (blue lines) are also shown. 
sunset occultations are located near the equator while sunrise occultations are situated at high latitudes south. The sunset ozone retrieved vmr reach up to $20 \%$ difference when the asymmetry of the atmosphere is considered. At sunrise, the impact of gradients on the retrievals is negligible. This behavior can be explained by the specific location of sunrise occultations, all situated at high latitudes in the South. It is expected from the GCM model that gradients are important for sunrise retrievals near the equator.

In order to study the effects of ozone gradients at different latitudes and seasons, and in particular to investigate the differences between sunrise/sunset conditions, we plan to extend the analysis to the whole SPICAM database and to NOMAD/ExoMars observations.

\section{Acknowledgments}

The research leading to these results has received funding from the European Unions Horizon 2020 Programme (H2020-Compet-08-2014) under grant agreement UPWARDS-633127. SA is supported by the FNRS CRAMIC project under grant number T.0171.16. This project acknowledges funding by the Belgian Science Policy Office (BELSPO), with financial and contractual coordination by the ESA Prodex Office (PEA4000121493). This work was supported by the Belgian Fonds de la Recherche Scientifique FNRS under grant number 30442502 (ET_HOME) and through the BRAIN Research contract BR/143/A2/SCOOP.

SPICAM-UV dataset is available through the European Space Agency's Planetary Science Archive (PSA). Ozone profiles will be later available through the VESPA (Virtual European Solar and Planetary Access) interface (http://vespa.obspm.fr). 


\section{Appendix A. Retrieval}

The ASIMUT retrieval module is based on the use of the Optimal Estimation Method , in which a priori information is used to represent the best statistical knowledge of the state of the atmosphere to be retrieved, prior to any measurement. The purpose of the retrieval is then to find the approximation of the true state at the atmosphere which agrees best with both the measurement and the a priori information. The general forward radiative transfer equation can be written as:

$$
\mathbf{y}=\mathbf{f}(\mathbf{x}, \mathbf{b})+\epsilon
$$

where $\mathbf{y}$ is the measurement vector (the measured radiance), $\mathbf{x}$ is the state vector (the vertical profiles to be retrieved), $\mathbf{b}$ represents the additional parameters used by the forward model $\mathbf{f}$, and $\epsilon$ is the random measurement noise. The forward function $\mathbf{f}$ describes the complete physics of the measurement, including the description of the instrument. $\mathbf{b}$ is a vector of model parameters (such as spectral line data, calibration parameters, etc.) that are not perfectly known by the observer. They are a possible source of random or systematic differences between calculated and measured values of $\mathbf{y}$.

In the case of a moderately nonlinear problem, the best estimate $\hat{\mathbf{x}}$ of the solution of Eq. A.1 is found by solving iteratively

$$
\mathbf{x}_{i+1}=\mathbf{x}_{a}+\mathbf{G}_{i}\left[\mathbf{y}-\mathbf{f}\left(\mathbf{x}_{\mathbf{i}}\right)+\mathbf{K}_{i}\left(\mathbf{x}_{i}-\mathbf{x}_{a}\right)\right]
$$

where $x_{a}$ is the a priori constraint. The Jacobian matrix $\mathbf{K}$ is defined by the following expression:

$$
\mathbf{K}=\frac{\partial \mathbf{f}}{\partial \mathbf{x}}
$$

and the Gain matrix $\mathbf{G}$ is defined by:

$$
\mathbf{G}_{i}=\left(\mathbf{S}_{a}^{-1}+\mathbf{K}_{i}^{T} \mathbf{S}_{e}^{-1} \mathbf{K}_{i}\right)^{-1} \mathbf{K}_{i}^{T} \mathbf{S}_{e}^{-1}
$$

where $\mathbf{S}_{e}$ is the error covariance matrix of the measurements, and $\mathbf{S}_{a}$ the a priori covariance matrix. $\mathbf{S}_{e}$ is usually chosen to be diagonal, characterizing all the sources of systematic and random errors on the measured radiance. 
The a priori covariance matrices $\left(\mathbf{S}_{a}\right)$ represents the variability of the gas/aerosol considered. Here ASIMUT considered diagonal matrices with off-diagonal terms added as Gaussian

$$
S_{a}(i, j)=\sqrt{S_{a}(i, i) S_{a}(j, j)} \exp \left(-\left(\frac{z_{i}-z_{j}}{l_{c}}\right)^{2}\right)
$$

to account for correlations between the concentrations at different altitudes $\left(z_{i}\right.$ is the altitude of level $\mathrm{i}, l_{c}$ is the vertical correlation length).

The convergence is attained when the two following conditions are met:

$$
\begin{aligned}
& d_{i}^{2}=\left(\mathbf{x}_{i}-\mathbf{x}_{i+1}\right)^{T} \mathbf{S}^{-1}\left(\mathbf{x}_{i}-\mathbf{x}_{i+1}\right)<<<n \\
& d_{i}^{2}=\left(\mathbf{f}\left(\mathbf{x}_{i+1}\right)-\mathbf{f}\left(\mathbf{x}_{i}\right)\right)^{T} \mathbf{S}_{\delta y}^{-1}\left(\mathbf{f}\left(\mathbf{x}_{i+1}\right)-\mathbf{f}\left(\mathbf{x}_{i}\right)\right)<<m
\end{aligned}
$$

with $n$ the number of parameters to retrieve, $m$ the number of observed points, and

$$
\begin{aligned}
& \delta y=\mathbf{y}-\mathbf{f}(\hat{\mathbf{x}}) \\
& \mathbf{S}_{\delta y}=\mathbf{S}_{e}\left(\mathbf{K} \mathbf{S}_{a} \mathbf{K}_{/}^{T}\right)^{-1} \mathbf{S}_{e}
\end{aligned}
$$

The first expression represents the convergence condition on the fitted parameters, and the second on the difference between observed and simulated spectra.

The total error decomposes into several contributions, i.e. the smoothing error $\left(\mathbf{S}_{\text {smoothing }}\right)$, the measurement error $\left(\mathbf{S}_{\text {measur }}\right)$ and the forward model parameters error $\left(\mathbf{S}_{\text {model }}\right)$.

$$
\mathbf{S}=\mathbf{S}_{\text {smoothing }}+\mathbf{S}_{\text {measur }}+\mathbf{S}_{\text {model }}
$$

In this work we have not considered the last term $\left(\mathbf{S}_{\text {model }}\right)$. The measurement error propagates from the instrumental noise. Its covariance is given by:

$$
\mathbf{S}_{\text {measur }}=\mathbf{G S}_{e} \mathbf{G}^{T}
$$

444

The smoothing error accounts for the sensitivity of the measurements/forward model to the variable to be retrieved (i.e. the measurement/forward model system does not allow perfectly 
reproducing the true atmosphere, but a smoothed value of it). The resulting error is characterized by the following covariance matrix:

$$
\mathbf{S}_{\text {smoothing }}=(\mathbf{A}-\mathbf{I}) \mathbf{S}_{a}(\mathbf{A}-\mathbf{I})^{-1}
$$

where $\mathbf{I}$ is the indentity matrix, and $\mathbf{A}$ is the averaging kernel matrix. It is defined as the sensitivity of the retrieved state (hereafter symbolized by $\hat{\mathbf{x}}$ ) to the true state $(\mathbf{x})$ and can be calculated as:

$$
\mathbf{A}=\frac{\partial \hat{\mathbf{x}}}{\partial \mathbf{x}}=\mathbf{G K}
$$

The rows of $\mathbf{A}$ define an averaging kernel function (AVK) for each element of $\hat{x}$, which peaks at the altitude from where most of the information is coming. In other words, the AVK provide an estimation of the vertical sensitivity of the retrieval and peak at the altitude of maximum sensitivity. The trace of the A matrix gives the degrees of freedom for signal (DOFS), defined as the number of independent pieces of information in the retrieved profile.

Finally the sum of these covariances associated to these different uncertainties provide an estimation of the total error on the retrieved parameters. One can show that the covariance matrix associated to $\hat{x}$ is given by:

$$
\mathbf{S}=\left(\mathbf{S}_{a}^{-1}+\mathbf{K}_{i}^{T} \mathbf{S}_{e}^{-1} \mathbf{K}_{i}\right)^{-1}
$$

The square root of the diagonal elements of $\mathbf{S}$ can be seen as the error on the retrieved parameters.

\section{References}

Bertaux, J.L., Korablev, O., Perrier, S., Quémerais, E., Montmessin, F., Leblanc, F., Lebonnois, S., Rannou, P., Lefèvre, F., Forget, F., Fedorova, A., Dimarellis, E., Reberac, A., Fonteyn, D., Chaufray, J.Y., Guibert, S., 2006. SPICAM on Mars Express: Observing modes and overview of UV spectrometer data and scientific results. Journal of Geophysical Research (Planets) 111. doi:10.1029/2006JE002690. 
Boughner, R., Larsen, J.C., Natarajan, M., 1980. The influence of NO and $\mathrm{C} \ell \mathrm{O}$ variations at twilight on the interpretation of solar occultation measurements. Geophysical Research Letters 7, 231-234. doi:10.1029/GL007i004p00231.

Brion, J., Chakir, A., Daumont, D., Malicet, J., Parisse, C., 1993. High-resolution laboratory absorption cross section of $\mathrm{O}_{3}$. Temperature effect. Chemical Physics Letters 213, 610-612. doi:10.1016/0009-2614(93)89169-I.

Daerden, F., Neary, L., Viscardy, S., García Muñoz, A., Clancy, R.T., Smith, M.D., Encrenaz, T., Fedorova, A., 2019. Mars atmospheric chemistry simulations with the GEM-Mars general circulation model. Icarus 326, 197-224. doi:10.1016/j.icarus.2019.02.030.

Daumont, D., Brion, J., Charbonnier, J., Malicet, J., 1992. Ozone UV spectroscopy. I - Absorption cross-sections at room temperature. Journal of Atmospheric Chemistry 15, 145-155. doi:10. $1007 / \mathrm{BF} 00053756$.

Drummond, R., Vandaele, A.C., Daerden, F., Fussen, D., Mahieux, A., Neary, L., Neefs, E., Robert, S., Willame, Y., Wilquet, V., 2011. Studying methane and other trace species in the Mars atmosphere using a SOIR instrument. Planetary and Space Science 59, 292-298. doi:10. $1016 / j \cdot p s s .2010 .05 .009$.

Dubovik, O., Smirnov, A., Holben, B.N., King, M.D., Kaufman, Y.J., Eck, T.F., Slutsker, I., 2000. Accuracy assessments of aerosol optical properties retrieved from Aerosol Robotic Network (AERONET) Sun and sky radiance measurements. Journal of Geophysical Research 105, 97919806. doi:10.1029/2000JD900040.

Erwin, J., Neary, L., Daerden, F., Viscardy, S., Carine Vandaele, A., 2018. Creating high-spatial resolution atmospheric profiles from the GEM-Mars GCM for the investigation of Mars, in: European Planetary Science Congress, pp. EPSC2018-717.

Forget, F., Montmessin, F., Bertaux, J.L., González-Galindo, F., Lebonnois, S., Quémerais, E., Reberac, A., Dimarellis, E., López-Valverde, M.A., 2009. Density and temperatures of the upper Martian atmosphere measured by stellar occultations with Mars Express SPICAM. Journal of Geophysical Research (Planets) 114, 1004. doi:10.1029/2008JE003086. 
Gallery, W.O., Kneizys, F.X., Clough, S.A., 1983. Air mass computer program for atmospheric transmittance/radiance calculation: FSCATM. Technical Report.

Godson, W.L., 1953. The evaluation of infra-red radiative fluxes due to atmospheric water vapour. Quarterly Journal of the Royal Meteorological Society 79, 367-379. doi:10.1002/qj . 49707934104.

Goody, R.M., 1952. A statistical model for water-vapour absorption. Quarterly Journal of the Royal Meteorological Society 78, 638-640. URL: https://rmets.onlinelibrary . wiley.com/doi/abs/10.1002/qj.49707833820, doi:10.1002/qj.49707833820, arXiv:https://rmets.onlinelibrary.wiley.com/doi/pdf/10.1002/qj . 49707833820.

Huestis, D.L., Berkowitz, J., 2010. Critical Evaluation of the Photoabsorption Cross Section of $\mathrm{CO}_{2}$ from 0.125 to $201.6 \mathrm{~nm}$ at Room Temperature, in: AAS/Division for Planetary Sciences Meeting Abstracts \#42, p. 48.13.

Kochenova, S., De Mazière, M., Vandaele, A., Kerzenmacher, T., Letocart, V., Kumps, N., Willame, Y., 2011. Alvl 1.0: an advanced line-by-line radiative transfer model for the retrieval of atmospheric constituents from satellite and ground-based measurements.

Lebonnois, S., Quémerais, E., Montmessin, F., Lefèvre, F., Perrier, S., Bertaux, J.L., Forget, F., 2006. Vertical distribution of ozone on Mars as measured by SPICAM/Mars Express using stellar occultations. Journal of Geophysical Research (Planets) 111, E09S05. doi:10.1029/2005JE002643.

Lefèvre, F., Lebonnois, S., Montmessin, F., Forget, F., 2004. Three-dimensional modeling of ozone on Mars. Journal of Geophysical Research (Planets) 109, E07004. doi:10.1029/2004JE002268.

Lemoine, F.G., Neumann, G.A., Chinn, D.S., Smith, D.E., Zuber, M.T., Rowlands, D.D., Rubincam, D.P., Pavlis, D.E., 2001. Solutions for Mars Geophysical Parameters from Mars Global Surveyor Tracking Data, in: AGU Fall Meeting Abstracts, p. P42A.

Määttänen, A., Lefèvre, F., Montmessin, F., Listowski, C., Guilbon, S., Fedorova, A., Korablev, O., submitted to Icarus, 2019. Climatology of the ozone vertical distribution on Mars from SPICAM/MEX UV occultations. Submitted to Icarus, this issue, 2019. 
Määttänen, A., Listowski, C., Montmessin, F., Maltagliati, L., Reberac, A., Joly, L., Bertaux, J.L., 2013. A complete climatology of the aerosol vertical distribution on Mars from MEx/SPICAM UV solar occultations. Icarus 223, 892-941. doi:10.1016/j.icarus.2012.12.001.

Malicet, J., Daumont, D., Charbonnier, J., Parisse, C., Chakir, A., Brion, J., 1995 . Ozone UV spectroscopy. II. Absorption cross-sections and temperature dependence. Journal of Atmospheric Chemistry 21, 263-273. doi:10.1007/BF00696758.

Markwardt, C.B., 2009. Non-linear Least-squares Fitting in IDL with MPFIT, in: Bohlender, D.A., Durand, D., Dowler, P. (Eds.), Astronomical Data Analysis Software and Systems XVIII, p. 251. arXiv:0902.2850.

Millour, E., Forget, F., González-Galindo, F., Spiga, A., Lebonnois, S., Montabone, L., Lewis, S.R., Read, P.L., López-Valverde, M.A., Gilli, G., Lefèvre, F., Montmessin, F., Desjean, M.C., Huot, J.P., McD/Gcm Development Team, 2008. The Latest (Version 4.3) Mars Climate Database, in: Third International Workshop on The Mars Atmosphere: Modeling and Observations, p. 9029.

Mishchenko, M., Travis, L.D., 1998. Capabilities and limitations of a current FORTAN implementation of the T-matrix method for randomly oriented, rotationally symmetric scatterers. Journal of Quantitative Spectroscopy and Radiative Transfer 60, 309-324. doi:10.1016/S0022-4073(98) 00008-9.

Montmessin, F., Bertaux, J.L., Quémerais, E., Korablev, O., Rannou, P., Forget, F., Perrier, S., Fussen, D., Lebonnois, S., Rébérac, A., Dimarellis, E., 2006. Subvisible $\mathrm{CO}_{2}$ ice clouds detected in the mesosphere of Mars. Icarus 183, 403-410. doi:10.1016/j.icarus .2006.03.015.

Natarajan, M., Deaver, L.E., Thompson, E., Magill, B., 2005. Impact of twilight gradients on the retrieval of mesospheric ozone from HALOE. Journal of Geophysical Research (Atmospheres) 110, D13305. doi:10.1029/2004JD005719.

Neary, L., Daerden, F., 2018. The GEM-Mars general circulation model for Mars: Description and evaluation. Icarus 300, 458-476. doi:10.1016/j.icarus.2017.09.028.

Nevejans, D., Neefs, E., van Ransbeeck, E., Berkenbosch, S., Clairquin, R., de Vos, L., Moelans, W., Glorieux, S., Baeke, A., Korablev, O., Vinogradov, I., Kalinnikov, Y., Bach, B., Dubois, J.P., Villard, E., 2006. Compact high-resolution spaceborne echelle grating spectrometer with 
acousto-optical tunable filter based order sorting for the infrared domain from 2.2 to $4.3 \mu \mathrm{m}$. Applied Optics 45, 5191-5206. doi:10.1364/A0.45.005191.

O’Neill, N., Royer, A., 1993. Extraction of bimodal aerosol-size distribution radii from spectral and angular slope (Angstrom) coefficients. Applied Optics 32, 1642-1645. doi:10.1364/AO.32. 001642.

Parkinson, W.H., Rufus, J., Yoshino, K., 2003. Absolute absorption cross section measurements of $\mathrm{CO}_{2}$ in the wavelength region 163-200 nm and the temperature dependence. Chemical Physics 290, 251-256. doi:10.1016/S0301-0104(03)00146-0.

Quémerais, E., Bertaux, J.L., Korablev, O., Dimarellis, E., Cot, C., Sandel, B.R., Fussen, D., 2006. Stellar occultations observed by SPICAM on Mars Express. Journal of Geophysical Research (Planets) 111, 9. doi:10.1029/2005JE002604.

Robert, S., Camy-Peyret, C., Daerden, F., De Mazière, M., De Wachter, E., Neary, L., Vandenbussche, S., Vandaele, A.C., 2017. Two test-cases for synergistic detections in the Martian atmosphere: Carbon monoxide and methane. Journal of Quantitative Spectroscopy and Radiative Transfer 189, 86-104. doi:10.1016/j.jqsrt.2016.11.003.

Robert, S., Vandaele, A.C., Thomas, I., Willame, Y., Daerden, F., Delanoye, S., Depiesse, C., Drummond, R., Neefs, E., Neary, L., Ristic, B., Mason, J., Lopez-Moreno, J.J., RodriguezGomez, J., Patel, M.R., Bellucci, G., Vandaele, A.C., Lopez Moreno, J.J., Bellucci, G., Patel, M., Allen, M., Altieri, F., Aoki, S., Bolsée, D., Clancy, T., Cloutis, E., Daerden, F., Depiesse, C., Fedorova, A., Formisano, V., Funke, B., Fussen, D., Garcia- Comas, M., Geminale, A., Gérard, J.C., Gillotay, D., Giuranna, M., Gonzalez-Galindo, F., Ignatiev, N., Kaminski, J., Karatekin, O., Kasaba, Y., Lefèvre, F., Lewis, S., Ló pez-Puertas, M., López-Valverde, M., Mahieux, A., Mason, J., McConnell, J., Mumma, M., Neary, L., Neefs, E., Novak, R., Renotte, E., Robert, S., Sindoni, G., Smith, M., Thomas, I.R., Trokhimovskiy, A., Vander Auwera, J., Villanueva, G., Viscardy, S., Whiteway, J., Willame, Y., Wilquet, V., Wolff, M., Alonso- Rodrigo, G., Aparicio del Moral, B., Barzin, P., BenMoussa, A., Berkenbosch, S., Biondi, D., Bonnewijn, S., Candini, G., Clairquin, R., Cubas, J., Delanoye, S., Giordanengo, B., Gissot, S., Gomez, A., Zafra, J.J., Leese, M., Maes, J., Mazy, E., Mazzoli, A., Meseguer, J., Morales, R., Orban, A., Pastor-Morales, M., PerezGrande, I., Ristic, B., Rodriguez-Gomez, J., Saggin, B., Samain, V., Sanz Andres, A., Sanz, R., 
Simar, J.F., Thibert, T., NOMAD Team, 2016. Expected performances of the NOMAD/ExoMars instrument. Planetary and Space Science 124, 94-104. doi:10.1016/j.pss.2016.03.003.

Rodgers, C.D., 2000. Inverse Methods for Atmospheric Sounding: Theory and Practice. doi:10. $1142 / 3171$

Sander, S.P., Abbatt, J., Barker, J., Burkholder, J., Friedl, R., Golden, D., Huie, R., Kolb, C., Kurylo, M., Moortgat, G., Orkin, V., Wine, P., 2011. Chemical kinetics and photochemical data for use in atmospheric studies.

Serdyuchenko, A., Gorshelev, V., Weber, M., Chehade, W., Burrows, J.P., 2014. High spectral resolution ozone absorption cross-sections - Part 2: Temperature dependence. Atmospheric Measurement Techniques 7, 625-636. doi:10.5194/amt-7-625-2014.

Smith, D.E., Zuber, M.T., Solomon, S.C., Phillips, R.J., Head, J.W., Garvin, J.B., Banerdt, W.B., Muhleman, D.O., Pettengill, G.H., Neumann, G.A., Lemoine, F.G., Abshire, J.B., Aharonson, O., Brown, David, C., Hauck, S.A., Ivanov, A.B., McGovern, P.J., Zwally, H.J., Duxbury, T.C., 1999. The Global Topography of Mars and Implications for Surface Evolution. Science 284, 1495. doi:10.1126/science.284.5419.1495.

Sneep, M., Ubachs, W., 2005. Direct measurement of the Rayleigh scattering cross section in various gases. Journal of Quantitative Spectroscopy and Radiative Transfer 92, 293-310. doi:10.1016/ j.jqsrt.2004.07.025.

Spurr, R.J.D., 2006. VLIDORT: A linearized pseudo-spherical vector discrete ordinate radiative transfer code for forward model and retrieval studies in multilayer multiple scattering media. Journal of Quantitative Spectroscopy and Radiative Transfer 102, 316-342. doi:10.1016/j . jqsrt.2006.05.005.

Trompet, L., Mahieux, A., Ristic, B., Robert, S., Wilquet, V., Thomas, I.R., Vandaele, A.C., Bertaux, J.L., 2016. Improved algorithm for the transmittance estimation of spectra obtained with SOIR/Venus Express. Applied Optics 55, 9275. doi:10.1364/A0.55.009275.

Vandaele, A.C., De Mazière, M., Drummond, R., Mahieux, A., Neefs, E., Wilquet, V., Korablev, O., Fedorova, A., Belyaev, D., Montmessin, F., Bertaux, J.L., 2008. Composition of the Venus 
mesosphere measured by Solar Occultation at Infrared on board Venus Express. Journal of Geophysical Research (Planets) 113, E00B23. doi:10.1029/2008JE003140.

Vandaele, A.C., Kruglanski, M., de Mazière, M., 2006. Modeling and Retrieval of Atmospheric Spectra Using ASIMUT, in: Atmospheric Science Conference, p. 71.

Vandaele, A.C., Lopez-Moreno, J.J., Patel, M.R., Bellucci, G., Daerden, F., Ristic, B., Robert, S., Thomas, I.R., Wilquet, V., Allen, M., Alonso-Rodrigo, G., Altieri, F., Aoki, S., Bolsée, D., Clancy, T., Cloutis, E., Depiesse, C., Drummond, R., Fedorova, A., Formisano, V., Funke, B., González-Galindo, F., Geminale, A., Gérard, J.C., Giuranna, M., Hetey, L., Ignatiev, N., Kaminski, J., Karatekin, O., Kasaba, Y., Leese, M., Lefèvre, F., Lewis, S.R., López-Puertas, M., LópezValverde, M., Mahieux, A., Mason, J., McConnell, J., Mumma, M., Neary, L., Neefs, E., Renotte, E., Rodriguez-Gomez, J., Sindoni, G., Smith, M., Stiepen, A., Trokhimovsky, A., Vander Auwera, J., Villanueva, G., Viscardy, S., Whiteway, J., Willame, Y., Wolff, M., 2018. NOMAD, an Integrated Suite of Three Spectrometers for the ExoMars Trace Gas Mission: Technical Description, Science Objectives and Expected Performance. ssr 214, 80. doi:10.1007/s11214-018-0517-2.

Vandaele, A.C., Mahieux, A., Robert, S., Berkenbosch, S., Clairquin, R., Drummond, R., Letocart, V., Neefs, E., Ristic, B., Wilquet, V., Colomer, F., Belyaev, D., Bertaux, J.L., 2013. Improved calibration of SOIR/Venus Express spectra. Optics Express 21, 21148. doi:10.1364/OE.21. 021148.

Vandenbussche, S., Kochenova, S., Vandaele, A.C., Kumps, N., De Mazière, M., 2013. Retrieval of desert dust aerosol vertical profiles from IASI measurements in the TIR atmospheric window. Atmospheric Measurement Techniques 6, 2577-2591. doi:10.5194/amt-6-2577-2013.

Willame, Y., Vandaele, A.C., Depiesse, C., Lefèvre, F., Letocart, V., Gillotay, D., Montmessin, F., 2017. Retrieving cloud, dust and ozone abundances in the Martian atmosphere using SPICAM/UV nadir spectra. Planetary and Space Science 142, 9-25. doi:10.1016/j.pss.2017.04. 011. 


\section{Highlights}

- We investigated the impact of gradients along the LOS of a solar occultation experiment

- We focused on the retrieval of ozone using observations acquired by SPICAM/MEx

- We implemented a radiative transfer code (ASIMUT) to take into account gradients

- We used the diurnal variations in the ozone concentration obtained from a GCM (GEM-Mars)

- The impact of gradients on ozone retrievals is strongly related to the GCM model results. 